\title{
The Transcription Factor Con7-1 Is a Master Regulator of Morphogenesis and Virulence in Fusarium oxysporum
}

\author{
Carmen Ruiz-Roldán, ${ }^{1}$ Yolanda Pareja-Jaime, ${ }^{1}$ José Antonio González-Reyes, ${ }^{2}$ and M. Isabel G. Roncero ${ }^{1}$ \\ ${ }^{1}$ Departamento de Genética, and ²Departamento de Biología Celular, Fisiología e Inmunología, Universidad de Córdoba, \\ Campus de Excelencia Agroalimentario (ceiA3), E-14071 Córdoba, Spain
}

Submitted 14 July 2014. Accepted 24 September 2014.

\begin{abstract}
Previous studies have demonstrated the essential role of morphogenetic regulation in Fusarium oxysporum pathogenesis, including processes such as cell-wall biogenesis, cell division, and differentiation of infection-like structures. We identified three $F$. oxysporum genes encoding predicted transcription factors showing significant identities to $\mathrm{Mag}$ naporthe oryzae Con7p, Con7-1, plus two identical copies of Con7-2. Targeted deletion of $\operatorname{con} 7-1$ produced nonpathogenic mutants with altered morphogenesis, including defects in cell wall structure, polar growth, hyphal branching, and conidiation. By contrast, simultaneous inactivation of both con 7-2 copies caused no detectable defects in the resulting mutants. Comparative microarray-based gene expression analysis indicated that Con 7-1 modulates the expression of a large number of genes involved in different biological functions, including host-pathogen interactions, morphogenesis and development, signal perception and transduction, transcriptional regulation, and primary and secondary metabolism. Taken together, our results point to Con 7-1 as general regulator of morphogenesis and virulence in F. oxysporum.
\end{abstract}

The early stages during pathogen-host interactions are crucial for the outcome of infection. Genes involved in the different stages of infection such as adhesion to the host surface, differentiation of infection-like structures, and penetration are under a complex regulation, which is mediated by mostly unknown transcription factors (TF). During recent years, a number of TF required for pathogenicity have been identified in Fusarium spp. In most cases, the specific function of these transcriptional regulators has not been clearly elucidated.

The GATA-type TF AreA is essential for nitrogen utilization and pathogenicity in Fusarium fujikuroi, F. oxysporum, and $F$. verticillioides (Divon et al. 2006; Kim and Woloshuk 2008; Tudzynski et al. 1999). The homeodomain transcription factor Ste12 controls invasive growth and virulence downstream of Fmk1 in the mitogen-activated protein kinase (MAPK) cascade in both $F$. oxysporum and F. graminearum (Garcia-Sanchez et al. 2010; Gu et al. 2014; Rispail and Di Pietro 2009).

TF involved in secondary metabolism have also been shown to be essential for pathogenicity. The $\mathrm{Zn}_{2} \mathrm{Cys}_{6}$ factor ZFRI is

Corresponding author: C. Ruiz-Roldán; Telephone: (+34) 957218981; Fax: (+34) 957212072; E-mail: ge2rurom@uco.es

* The $e$-Xtra logo stands for "electronic extra" and indicates that eight supplementary figures, four supplementary tables, and two supplementary movies are published online.

(C) 2015 The American Phytopathological Society involved in fumonisin production and colonization of maize kernels by $F$. verticillioides (Bluhm et al. 2008). The F. graminearum b-ZIP TF Zifl is necessary for sexual reproduction, deoxynivalenol production, and virulence on flowering wheat heads (Wang et al. 2011). The velvet protein complex, integrated by the regulators VeA, VelB, VelC, and LaeA, controls secondary metabolism and virulence in F. fujikuroi (Wiemann et al. 2010), F. verticillioides (Butchko et al. 2012; Myung et al. 2009, 2012), F. oxysporum (Lopez-Berges et al. 2013), and F. graminearum (Kim et al. 2013). The APSES (Asm1p, Phd1p, Sok2p, Efg1p, and StuAp) transcription factor FgStuA regulates spore development, pathogenicity, and secondary metabolism in F. graminearum (Lysoe et al. 2011). F. oxysporum VelB, orthologous to members of the fungal Velvet protein family, regulates development and secondary metabolism (Lopez-Berges et al. 2009).

Fow2 and Sge1 are required for root invasion and efficient colonization of plant tissues by $F$. oxysporum (Imazaki et al. 2007; Michielse et al. 2009a). Fow2 belongs to the $\mathrm{Zn}_{2} \mathrm{Cys}_{6}$ family of TF, whereas Sge1 is orthologous to Wor1, a regulator for morphological switching in Candida albicans. Interestingly, both $\mathrm{TF}$ are dispensable for root attachment, vegetative growth, and utilization of carbon sources. FoCti6 is also required for full pathogenicity in $F$. oxysporum (Michielse et al. 2009a).

The multicopy gene $f t f l$ encodes a transcription factor only present in highly virulent strains of $F$. oxysporum and is specifically induced during the early stages of infection (Ramos et al. 2007). The b-ZIP TF ZifF1, involved in virulence of $F$. graminearum, is unique to filamentous fungi and lacks apparent orthologs in yeast (Seong et al. 2005).

The $\mathrm{pH}$-responsive TF $\mathrm{PacC}$ is a negative regulator of pathogenicity in $F$. oxysporum (Caracuel et al. 2003). XlnR regulates three xylanase genes involved in the pathogenicity of this fungus (Calero-Nieto et al. 2007). Ctf1 and Ctf2, regulating cutinolytic and lipolytic activities, are also necessary for full virulence in F. oxysporum (Bravo-Ruiz et al. 2013). Snt is involved in pathogenicity, hyphal growth, and conidiation in $F$. oxysporum f. sp. melonis (Denisov et al. 2011). An F. graminearum mutant affected in a gene encoding a putative GAL4_like fungal $\mathrm{Zn}_{2} \mathrm{Cys}_{6} \mathrm{TF}$ ( $F G S G_{-}$10057) exhibited drastic reduction in radial growth and was unable to spread beyond the initial infected spikelet (Dufresne et al. 2008).

Studies on the fungal pathogen $F$ oxysporum f. sp. lycopersici, the causal agent of tomato vascular wilt disease, have demonstrated the essential role of morphogenetic regulation in pathogenesis, including processes such as cell-wall biogenesis, cell division, and differentiation (Lopez-Berges et al. 2012; Lopez-Fernandez et al. 2013; Madrid et al. 2003; MartinUrdiroz et al. 2008; Michielse et al. 2009b; Rispail and Di 
Pietro 2009). On the other hand, Con7p has been described as a central regulator of infection-related morphogenesis in the rice blast fungus Magnaporthe oryzae (Odenbach et al. 2007). Con7p-deficient mutants are reduced in conidiation and unable to form appressoria and, thus, are nonpathogenic because they fail to penetrate the leaf surface (Odenbach et al. 2007; Shi et al. 1998). This TF regulates the expression of genes involved in cell wall biogenesis and remodeling, such as the class VI chitin synthase Chs7 (Odenbach et al. 2009) or the chitin-binding proteins $\mathrm{Cbp} 1$ and $\mathrm{Cbp} 2$, as well as signaling components such as the pathogenicity factor PTH11 and other G proteincoupled receptors. Here, we report the identification and functional analysis of Con7-1 and Con7-2, two F. oxysporum putative TF showing significant identities to $M$. oryzae Con $7 \mathrm{p}$. Deletion of $\operatorname{con} 7-1$ but not of con 7-2 severely impaired pathogenicity of $F$. oxysporum in both tomato plants and the nonvertebrate animal model Galleria mellonella. The $\Delta$ con7-1 mutants exhibited several morphological defects, including abnormal germination, branching, conidiation, and cell wall morphology. Comparative microarray-based gene expression analysis indicated that Con7-1 modulates the expression of a large number of genes involved in many different functions, including hostpathogen interactions, morphogenesis and development, signal perception and transduction, regulation of gene expression, and cell metabolism. Taken together, our results suggest that Con7-1 is a general regulator of morphogenesis and virulence in F. oxysporum.

\section{RESULTS}

Two orthologs of $M$. oryzae Con7p in F. oxysporum genome.

In order to identify sequences encoding for orthologs to $M$. oryzae Con $7 \mathrm{p}$ in the genome of the tomato pathogen $F$. oxysporum $\mathrm{f}$. sp. lycopersici, we performed an in silico search in the sequence database. The blast search revealed three predicted orthologs: FOXG_11503, FOXG_14029, and FOXG_ 12510. F. oxysporum FOXG_11503 (named con7-1) contains

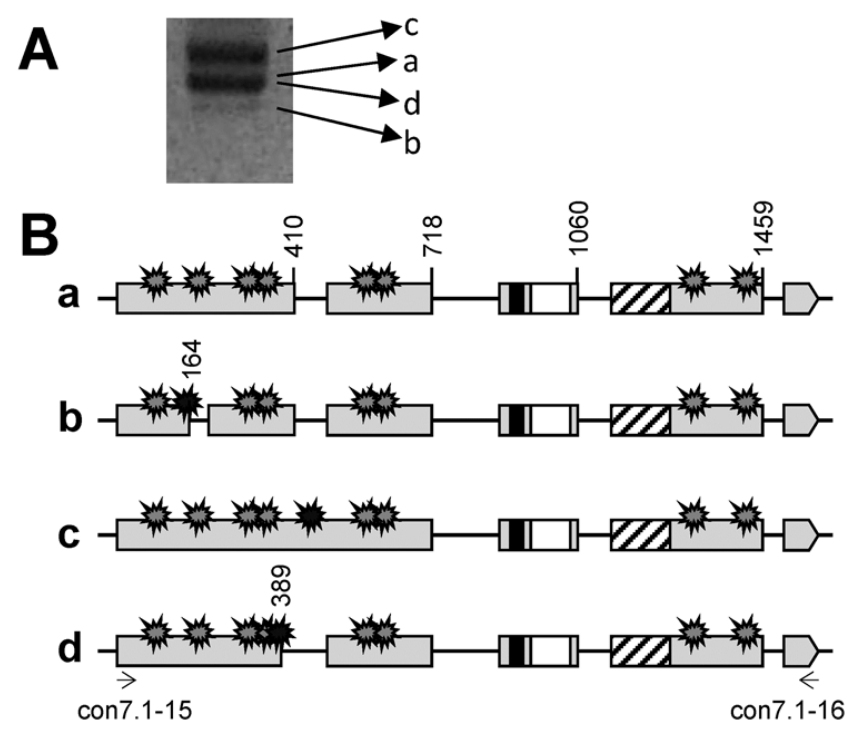

Fig. 1. Differential splicing of con $7-1$ introns. A, Reverse-transcriptase polymerase chain reaction analysis of con $7-1$ transcripts during vegetative growth of Fusarium oxysporum wild-type strain, using the primers indicated by arrows in B. Letters refer to drawings depicted in B. B, Schematic representation of con $7-1$ alternative transcripts. Boxes indicate Con7-1 conserved domains: black = nuclear localization signal; white = $\mathrm{C}_{2} \mathrm{H}_{2}$ zinc-finger DNA-binding domain; dashed = coiled-coil region. Stars indicate putative phosphorylation sites: gray = common to the four types of transcripts; black = exclusive of each type of transcript. Numbers indicate the position of the introns from the start codon. an open reading frame (ORF) of 1,538 bp interrupted by six introns of $60,96,75,161,66$, and $51 \mathrm{bp}$ located at positions $164,389,410,718,1,060$, and 1,459 , respectively, encoding a predicted protein of 419 amino acids (aa), which shares $69 \%$ identity with Con7p of M. oryzae. F. oxysporum FOXG_14029 and FOXG_12510 are identical copies located within duplicated genomic regions on the lineage-specific (LS) chromosomes 3 and 6 , respectively (hereafter named con7-2); they contain an ORF of 1,265 bp with three introns of 96, 168, and 68 bp located at positions 197, 526, and 875, respectively, encoding a predicted protein of 310 aa, with identities of $47.6 \%$ with $M$. oryzae Con 7p and $58.1 \%$ with $F$. oxysporum Con7-1 (Supplementary Fig. S1).

Analyses of $F$. oxysporum Con7 deduced proteins using CBS prediction and PROSITE tools revealed that they contain the highly conserved $\mathrm{Cys}_{2} \mathrm{His}_{2}$ zinc-finger DNA-binding motif, as well as a nuclear localization signal and a coiled-coil region. Similar to $M$. oryzae Con 7p, F. oxysporum Con 7 proteins also contain $\mathrm{C}$-terminal proline- and glutamine-rich regions.

To determine whether $F$. oxysporum con $7-1$ transcripts are differentially processed similarly to $M$. oryzae con $7 p$ (Odenbach et al. 2007), reverse-transcriptase polymerase chain reaction (RT-PCR) analyses using total RNA extracted from wild-type germlings were performed. Four different transcript sizes were obtained and further cloned and sequenced for their identification (Fig. 1A). Among the resulting clones, 57.7\% corresponded to transcripts which included introns 1 and 2 (Fig 1Ba); $23.1 \%$ to transcripts with unprocessed intron 2 (Fig. $1 \mathrm{Bb}) ; 15.4 \%$ to unprocessed introns 1, 2, and 3 (Fig. 1Bc); and, finally, $3.8 \%$ to transcripts with unprocessed intron 1 (Fig. 1Bd). The alternative intron splicing of con $7-1$ transcripts and their subsequent translation could generate four different protein versions containing specific putative phosphorylation sites as deduced by using the CBS prediction tool (Fig. 1B). Similar to M. oryzae Con 7p, the differentially spliced $F$. oxysporum Con7-1 N terminus encompasses a region where no specific conserved domains were detected according to CBS and PROSITE prediction tools.

\section{Con7-1 but not Con7-2 function}

is essential for full virulence of $\boldsymbol{F}$. oxysporum.

To analyze the role of Con7 proteins in the virulence of $F$. oxysporum, targeted gene replacement was performed in the wild-type background (Supplementary Figs. S2A and 3A). Hygromycin-resistant $\left(\mathrm{Hyg}^{\mathrm{R}}\right)$ transformants were initially analyzed by PCR amplification of the $5^{\prime}$ and $3^{\prime}$ flanking regions (data not shown), and putative deletion mutants were further confirmed by Southern analyses. Several transformants showed the expected shift in the hybridizing pattern from 3.4 to $1.8 \mathrm{~kb}$ for $\Delta$ con $7-1$ mutants or from 10.2 to $11.8 \mathrm{~kb}$ for simultaneous disruption of both copies of con7-2.

Complementation of the $\Delta$ con $7-1$ mutant was achieved by co-transformation with the wild-type allele and the phleomycin $(\mathrm{Phl})$ resistance cassette as selective marker. $\mathrm{Phl}^{\mathrm{R}}$ transformants expressing wild-type con $7-1$ transcripts (named c $\Delta$ con 7 1) were identified by RT-PCR analysis using primer pair con7.1-16 and con7.1-28 flanking intron 6 (Supplementary Table S1; Supplementary Fig. S4).

The role of Con7 proteins in $F$. oxysporum virulence was determined by plant infection assays, performed by immersing the roots of 2-week-old tomato plants in microconidial suspensions of the fungal strains. Severity of wilt symptoms in plants inoculated with the wild-type strain and the $\Delta$ con 7-2 mutant increased steadily throughout the experiment, showing characteristic wilt symptoms 12 days postinoculation (dpi), with most plants dead at 8 to 10 dpi. By contrast, plants inoculated with the $\Delta$ con $7-1$ mutant showed no visible disease symptoms 
and remained as healthy as the water controls throughout the experiment (Fig. 2A). Complementation of the $\Delta$ con $7-1 \mathrm{mu}-$ tant with a wild-type copy of the gene completely restored the virulence. To study the ability of the nonvirulent $\Delta$ con $7-1 \mathrm{mu}-$ tant to adhere to the tomato root surface, we performed microscopic observations of roots $24 \mathrm{~h}$ after inoculation with the different mutants and the wild-type strain. These analyses revealed that both the wild-type strain and the $\Delta \operatorname{con} 7-1$ mutant were able to attach, germinate, and form a dense mycelium network surrounding the root surface (Supplementary Fig. S5), thus indicating no major differences in root surface attachment between both strains. The ability of the $\Delta \operatorname{con} 7-1$ mutant to colonize tomato plant tissues was assessed by quantification of specific fungal DNA within stems using real-time PCR. The amount of fungal biomass increased during the course of infection in wild-type-inoculated plants (up to $6.8 \%$ of total DNA within infected tissues at 7 dpi) (Fig. 2B). A significant decrease in the amount of fungal DNA was observed in plants inoculated with the $\Delta c o n 7-1$ mutant $(<0.05 \%$ of total DNA from infected tissues at $7 \mathrm{dpi}$ ). No significant differences were observed between the $c \Delta c o n 7-1$ and the wild-type strains. No DNA amplification was observed in the uninoculated controls. The ability of the $\operatorname{con} 7$ mutants to proliferate on living host tissue was also assayed on tomato fruit injected with microconidial suspensions of the different strains. The wild-type strain and the $\Delta$ con 7-2 mutant colonized and macerated the fruit tissue surrounding the sites of inoculation, forming a dense mycelium on these surfaces. By contrast, the $\Delta$ con $7-1$ mutant showed a significant decrease in the capacity for invading and macerating the fruit tissue (Supplementary Fig. S6). Complementation of the $\Delta \operatorname{con} 7-1$ mutant with a functional copy of the gene restored the wild-type phenotype. Taken together, these results indicate that Con7-1 but not Con7-2 is essential for full virulence of $F$. oxysporum on tomato plants.

In order to examine the role of Con7-1 in F. oxysporum virulence on animals, we performed infection experiments using the wax moth $G$. mellonella as host, recently described as a useful nonvertebrate infection model for studying virulence mechanisms of $F$. oxysporum on animal hosts (NavarroVelasco et al. 2011). Injection of wild-type microconidia into the hemocoel of $G$. mellonella resulted in rapid killing of the larvae (Fig. 2C). By contrast, the $\Delta$ con $7-1$ mutant showed a significant $(P<0.0001)$ reduction in killing, with $90 \%$ of larvae still alive 5 days after injection. The complemented strain c $\Delta \operatorname{con} 7-1$ did not show significant differences in killing efficiency compared with the wild-type strain, suggesting that deletion of con 7-1 severely impairs virulence of $F$. oxysporum on G. mellonella.

\section{Deletion of Con7-1 results in morphological defects in $F$. oxysporum.}

To investigate the physiological function of Con7-1, phenotypes of the $\Delta$ con $7-1$ mutant were compared with the wildtype strain. Monosporic colonies of the $\Delta \operatorname{con} 7-1$ mutant grown on potato dextrose agar (PDA) displayed an asymmetric morphology different from the wild-type or the $\mathrm{c} \Delta$ con $7-1$ strains that showed radial symmetry on solid surfaces (Fig. 3A and B). Microscopic observations of potato dextrose broth (PDB)grown germlings stained with Calcofluor white revealed a preferred unipolar pattern of conidial germination in the $\Delta$ con $7-1$ mutant, with most microconidia producing a single germ tube, in contrast to the wild-type or the $c \Delta \operatorname{con} 7-1$ strains, where most conidia displayed a bidirectional pattern, as previously described (Ruiz-Roldán et al. 2010) (Fig. 3C; Supplementary Fig. S7A). No significant differences were observed in the germination rates of the strains growing on PDB. However, the $\Delta \operatorname{con} 7-1$ mutant showed a significant delay in conidial germi- nation in synthetic medium (SM) broth compared with the wild-type or the complemented strains. In complete medium (PDB), the first hyphal branch points emerged after 9 to $10 \mathrm{~h}$ in the wild-type and the $\mathrm{c} \Delta \mathrm{con} 7-1$ strains, whereas no branches were detected until $14 \mathrm{~h}$ of incubation in the $\Delta$ con $7-1$ mutant (Fig. 3C). Furthermore, the $\Delta$ con $7-1$ mutant showed a 10 -h de-
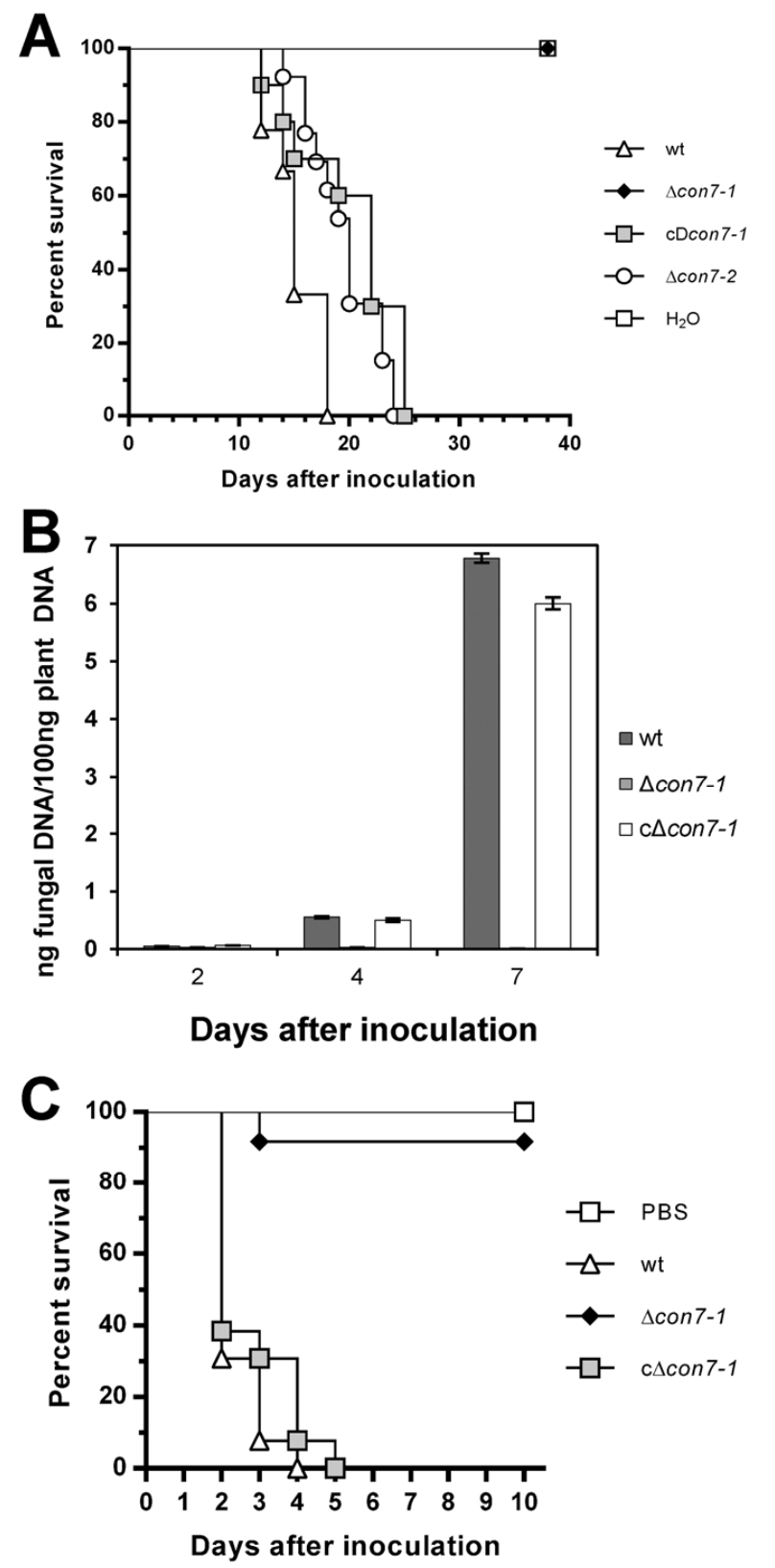

Fig. 2. Con7-1 function is required for Fusarium oxysporum full virulence. A, Virulence of $F$. oxysporum con7-deficient mutants on tomato plants ('Monika'). Groups of 10 plants were inoculated by immersing the roots into a suspension of $5 \times 10^{6}$ freshly obtained microconidia $\mathrm{ml}^{-1}$ of the wild type (wt), the $\Delta$ con $7-1$ or $\Delta$ con 7-2 mutants, and c $\Delta$ con $7-1$ complemented strain, and planted in minipots. Percent survival was recorded after different time points. Experiments were performed three times with similar results. Data shown are from one representative experiment. B, Detection of fungal genomic DNA (gDNA) during plant infection was performed by quantitative polymerase chain reaction analysis of total gDNA isolated from stems of plants infected with the indicated strains 2, 4, and 7 days postinoculation, using primer pairs specific for fungal DNA and referred to plant DNA. C, Mantel-Cox plots of Galleria mellonella larvae survival after injection of $1.6 \times 10^{5}$ microconidia of the indicated strains into the hemocoel and incubation at $30^{\circ} \mathrm{C}$. Experiments were performed three times with similar results. Data shown are from one representative experiment. 
lay in the growth rate when compared with the wild-type or the complemented strains in both PDB or SM broth. This delay in the $\Delta$ con 7-1 mutant was also evident when observed by time-lapse microscopy (Supplementary Movies S1 and S2). In addition, the $\Delta$ con $7-1$ mutant was defective in conidiation, as reflected by lower production of microconidia in liquid cul- tures compared with the wild-type or the $\mathrm{c} \Delta \operatorname{con} 7-1$ strains. Finally, transmission electron microscopy (TEM) observations of the cell wall of the $\Delta$ con $7-1$ mutant showed an electron-transparent layer threefold thicker than in the wild-type or the c $\Delta$ con 7-1 strains (Fig. 3D), suggesting defects in cell wall structure similar to those described for a chitin synthase mu-
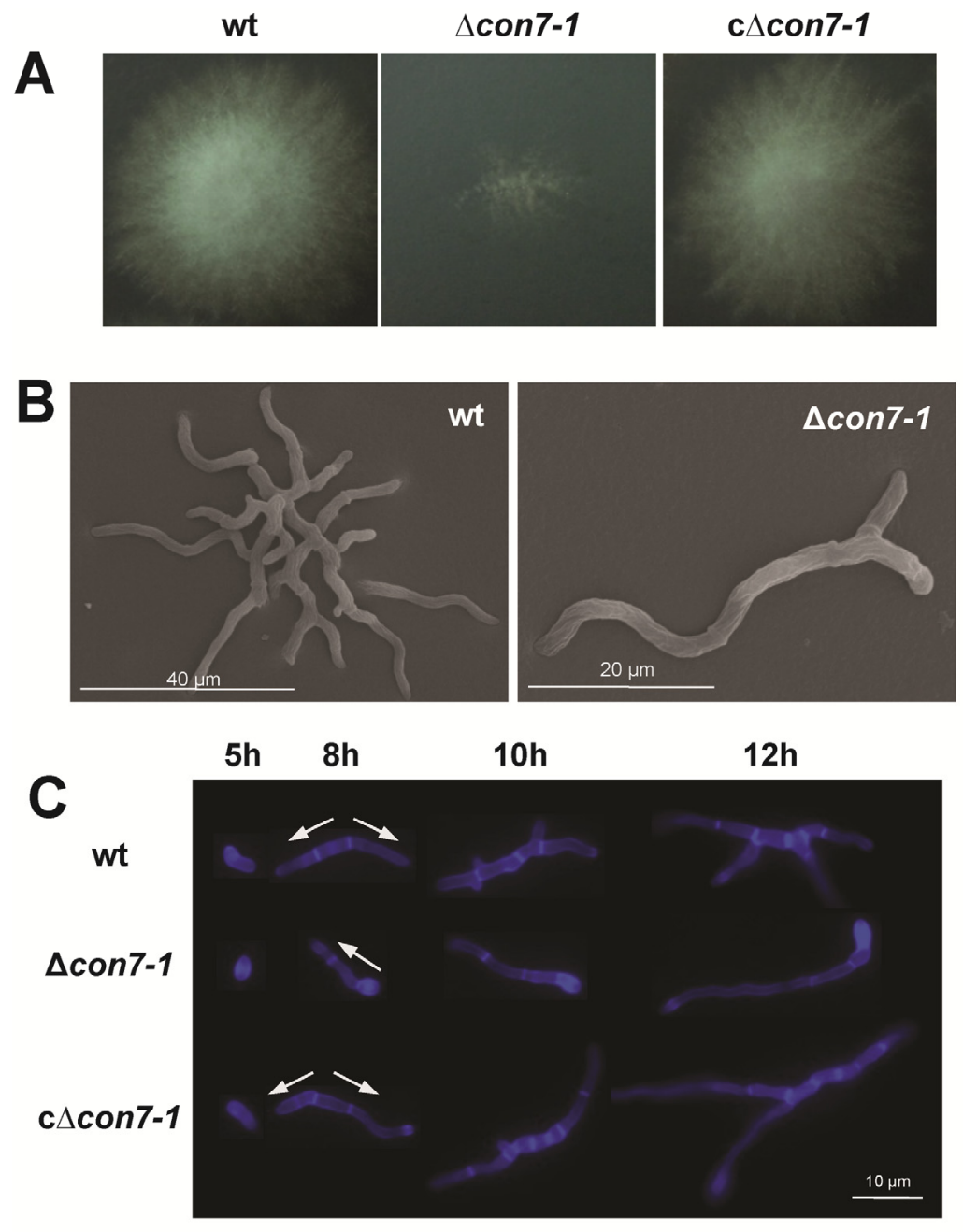

D
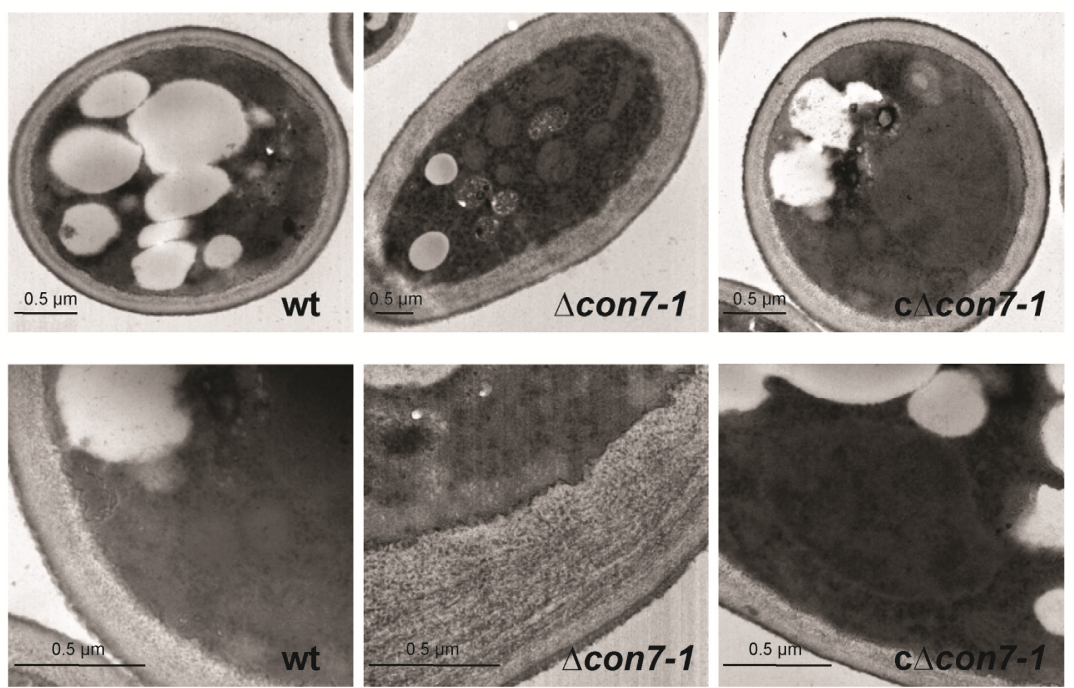

Fig. 3. Deletion of con7-1 results in morphological defects in Fusarium oxysporum. A, Morphology of 3-day-old colonies grown on potato dextrose agar (PDA) medium from one single microconidium of the indicated strains; wt = wild type. $\mathbf{B}$, Scanning electron micrographs showing germlings of the indicated strains grown for $24 \mathrm{~h}$ on PDA plates. C, Fluorescence microscopy images of germlings grown in potato dextrose broth medium for the indicated time periods and stained with Calcofluor white. Arrows indicate growth direction. D, Transmission electron micrographs showing spores of the indicated strains. 
tant of F. oxysporum (Martin-Urdiroz et al. 2008). These results demonstrate that $F$. oxysporum Con7-1 functions in germination, branching, conidiation, and cell wall morphology.

\section{Comparative transcriptomic analysis of $\Delta \operatorname{con} 7-1$ and the wild-type strain.}

In order to identify potential targets of the Con7-1 transcription factor, global RNA expression profiles of the wild type and $\Delta \operatorname{con} 7-1$ were compared. To normalize the growth delay of the mutant, total RNA was extracted from germlings grown for
$14 \mathrm{~h}$ for the wild-type strain and $24 \mathrm{~h}$ for $\Delta \operatorname{con} 7-1$. The search for differentially expressed genes was established as a minimum of 2.5-fold down- or upregulation in $\Delta$ con $7-1$ versus the wild type. In total, 1,054 genes were shown to be differentially expressed in $\Delta$ con $7-1,341$ of which corresponded to genes with unknown function (Supplementary Table S2). Con7-1dependent identified genes were broadly classified according to their predicted function, based on gene ontology (GO) using the UniProt-GO Annotation database and the Kyoto Encyclopedia of Genes and Genomes (KEGG) protein interaction

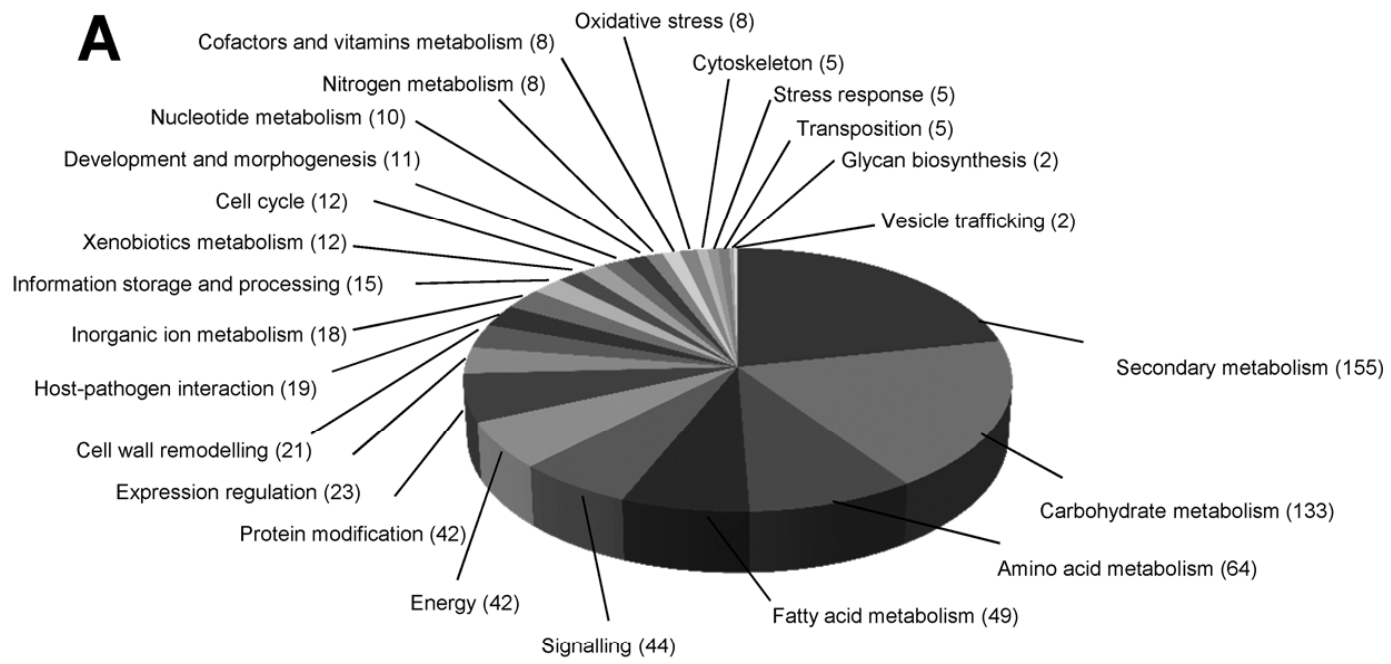

B

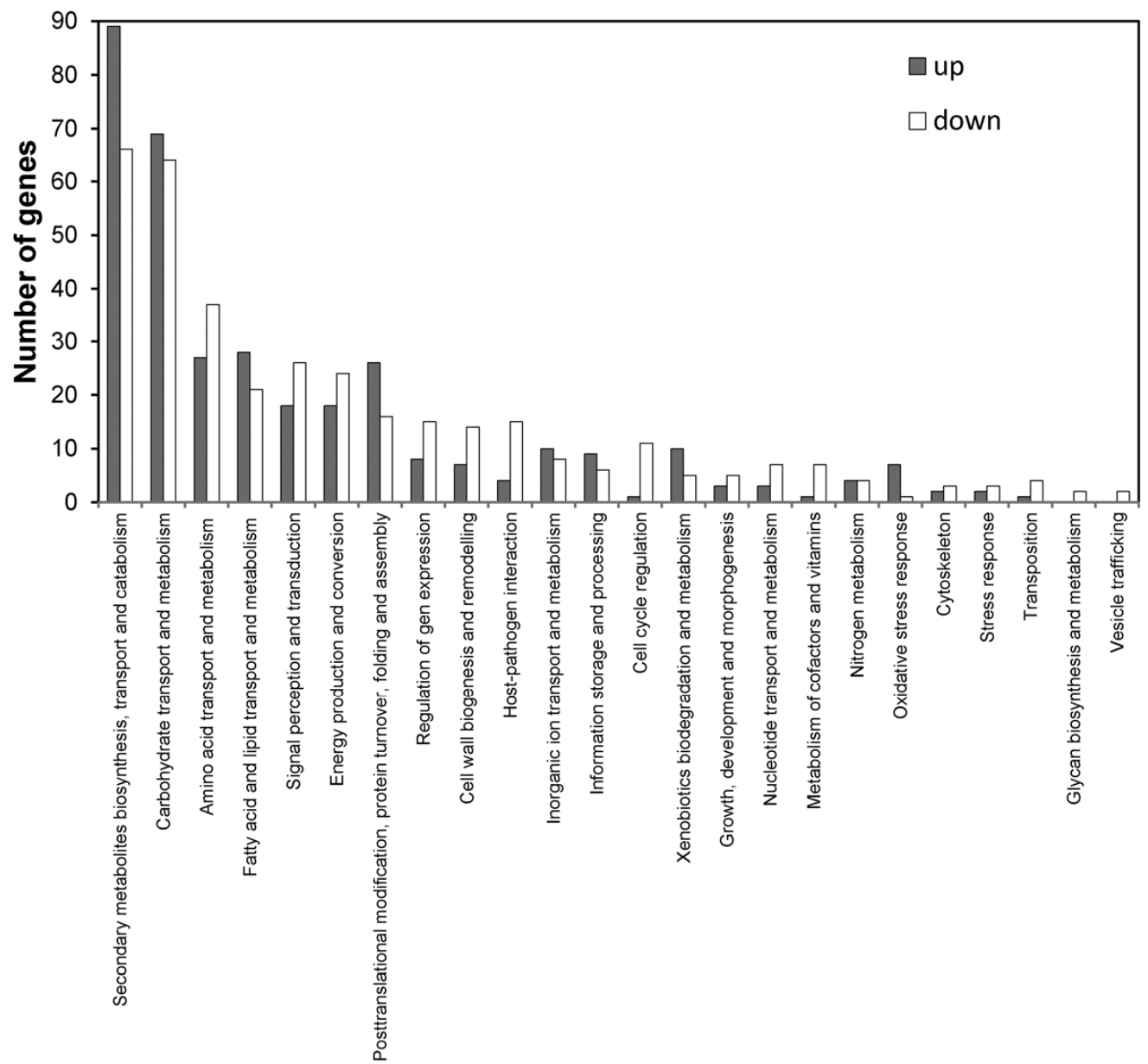

Fig. 4. Comparative transcriptomic analysis of $\Delta \operatorname{con} 7-1$ mutant and wild-type strain. A, Genes showing a minimum of 2 fold change in their expression levels were classified according to their biological function into gene ontology categories. The pie chart depicts the number of differentially expressed genes into each functional category. B, Number of up- and downregulated genes in the $\Delta$ con $7-1$ mutant in each functional category. 
pathways (Fig. 4A). Among the identified genes, 366 were downregulated while 347 were upregulated in $\Delta$ con $7-1$ (Fig. 4B). Interestingly, we found altered regulation of genes that may play a role in fungus-host interaction, including several hydrophobins, an adhesin, endopolygalacturonases, a cellulase, expansins, a tomatinase (Tom3), a secreted-in-xylem (SIX) protein (SIX9), two proteins similar to SIX8, a hypersensitive-response-inducing protein, or a protein similar to $O$ acetyltransferase CAS1 (Janbon et al. 2001), among others.

Altered expression of genes encoding putative proteins involved in the regulation of morphogenesis and development such as the Rho GTPase activating proteins Sac7 and Rag6, the Rho4-like GTPase, the conidiation-specific protein 10, or the cell wall protein PhiA, among others, were also detected. The $\Delta$ con $7-1$ mutant also displayed altered transcript levels of genes related to cytoskeleton, including a calpain cysteine protease (Futai et al. 1999), a phosphatidylinositol phosphate kinase (Foti et al. 2001), a microtubule associated protein, an actin depolymerization factor (cofilin), and an actin cytoskeleton protein (VIP1) (Pohlmann and Fleig 2010). Furthermore, several genes involved in cell cycle regulation were downregulated in $\Delta \operatorname{con} 7-1$, including a cell division protein (FtsK), a cell division cycle 2 protein kinase, a cyclin-dependent protein kinase (Cdck5), a serine/threonine-protein kinase (pctaire-2), a Cut9-interacting protein ( $\operatorname{Scn} 1)$, a cyclindependent protein tyrosine kinase and several protein kinase cyclin-negative regulators, the G2-specific protein tyrosine kinase (Nim-1), and the Cdc25 phosphatase. Additionally, genes involved in cell wall biogenesis and remodeling were differentially expressed in $\Delta$ con $7-1$, such as various chitin-

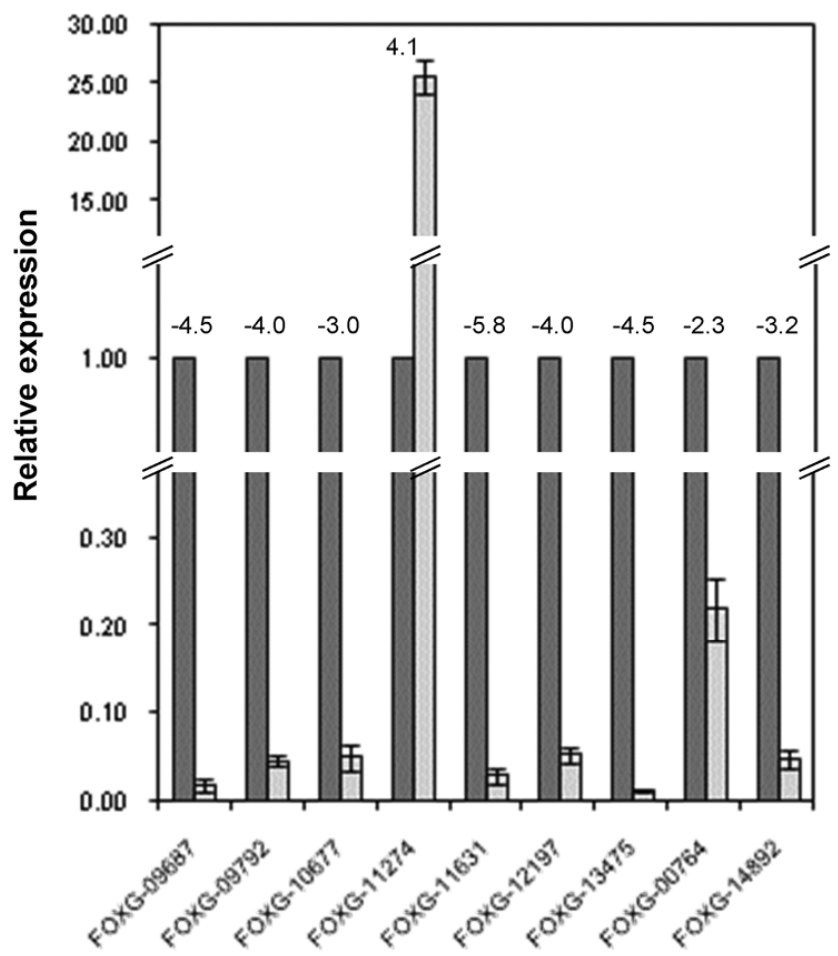

Fig. 5. Con7-1 mediates signal perception and cellular morphogenesis in Fusarium oxysporum. Expression levels of some of the identified genes responsible for G protein-coupled receptors, Rho GTPase proteins, and Rho GTPase activators were determined by quantitative reverse-transcriptase polymerase chain reaction analysis using total RNA from germlings of the wild-type strain (dark gray) or the $\Delta$ con $7-1$ mutant (light gray). Relative expression levels represent the mean cycle threshold values normalized to actin gene. Bars represent standard errors calculated from three independent experiments with three replicates each. Numbers above columns indicate relative protein abundance according to transcriptomic analyses. ases and glucanases, lectins, an autolysin, and a glycine-rich cell wall structural protein.

Genes involved in the oxidative stress response were upregulated in the mutant strain, including several peroxidases and catalases. Altered expression of a significant number of genes involved in signal perception and transduction, such as several serine-threonine protein kinases, Pth11-like G protein coupled receptors, a $\mathrm{G}$ protein coupled receptor involved in carbon sensing, a calcium/calmoduline-dependent protein kinase, a calmoduline-binding protein, calcineurin-like phosphoesterases, and an opsin, among others, were also detected. On the other hand, genes involved in regulation of gene expression were also altered. These included several $\mathrm{Zn}_{2} \mathrm{Cys}_{6^{-}}$, bZIP-, GAL4-like, and fungal-specific transcription factors, as well as a YTH domain-containing protein that has been proposed to mediate Ca-regulated gene expression in plants (Ok et al. 2005), and an amdA-like transcription factor involved in regulation of acetamidase amdS in Aspergillus nidulans (Lints et al. 1995). As expected, expression of con7-1 was altered in $\Delta$ con $7-1$ but only to a threefold lower level compared with the wild-type strain, probably due to unspecific cross-binding of con 7-1 probes to con 7-2 transcripts. Analysis of gene expression by RT-PCR confirmed the absence of con 7-1 transcripts in $\Delta \operatorname{con} 7-1$ compared with the wild-type and $\mathrm{c} \Delta \operatorname{con} 7-1$ strains, whereas no differences were detected in $\operatorname{con} 7-2$ expression between the different strains.

Finally, a large set of genes encoding proteins involved in secondary metabolite biosynthesis, catabolism, and secretion, in xenobiotics biodegradation, and in cell metabolism showed altered expression in $\Delta \operatorname{con} 7-1$. Among them, altered regulation of a high number of genes involved in carbohydrate transport and metabolism was detected. Interestingly, three genes encoding key enzymes involved in glycolysis (hexokinase [FOXG 12010], glucose-6-P isomerase [FOXG_02869], and phosphoglycerate mutase [FOXG_02606]) were upregulated in $\Delta$ con7-1, while two genes encoding gluconeogenesis regulatory enzymes (fructose 1,6-bisphosphatase [FOXG_12310] and phosphoenolpyruvate carboxykinase [FOXG_03418]) were downregulated, indicating significant alterations of glucose metabolism.

To validate the accuracy of the microarray experiments, real-time RT-PCR was performed to determine transcript levels of different gene categories: growth, development and morphogenesis, and signal perception and transduction. The results confirmed the differences previously observed in the regulation of all genes analyzed in $\Delta$ con7-1 (Fig. 5).

According to microarray analysis, a number of genes encoding putative chitinases were downregulated in $\Delta$ con7-1. An in silico search of the $F$. oxysporum genome database revealed the existence of 29 genes encoding putative chitinases; among them, 15 showed a putative signal peptide indicative of extracellular enzymes (Supplementary Table S3). To confirm that chitinase production was altered in $\Delta c o n 7-1$, intra- and extracellular chitinase activity was determined in the different strains. A drastic reduction of endo- and exochitinase activity of both intra- and extracellular protein extracts was detected in $\Delta$ con7-1 compared with the wild-type strain, while complementation of the mutant with a wild-type $\operatorname{con} 7-1$ allele restored the phenotype (Fig. 6), suggesting a defect in cell wall remodeling in the mutant strain.

The results of the microarray analyses suggest that production of catalases and peroxidases is enhanced in $\Delta$ con $7-1$. The functional significance of these results was determined by comparing the sensitivity to hydrogen peroxide of $\Delta$ con $7-1$ and the wild-type and complemented strains. Microconidia of $\Delta$ con 7-1 were markedly more resistant to the oxidative stress produced by hydrogen peroxide than either the wild type or the c $\Delta$ con 7-1 complemented strain (Fig. 7). These results sup- 
port the observations from the transcriptional profiling experiments, suggesting that Con7-1 is a negative regulator of the oxidative stress responses. Additionally, a significant increased sensitivity to the membrane interacting agent sodium dodecyl sulfate (SDS) was shown by $\Delta$ con $7-1$ compared with the wild type or c $\Delta$ con 7-1 complemented strains (Fig. 7), supporting the conclusion that the altered cell wall structure in the mutant may influence membrane susceptibility to these perturbing agents.

As mentioned above, the $\Delta$ con $7-1$ mutant showed downregulation of several hydrophobin-encoding genes. To determine whether the $\Delta$ con $7-1$ mutant is affected in surface hydrophobicity, water droplets containing alcian blue were placed on the surface of fungal colonies grown on minimal medium (MM). After $1 \mathrm{~h}$, the drops were still suspended on the hydrophobic
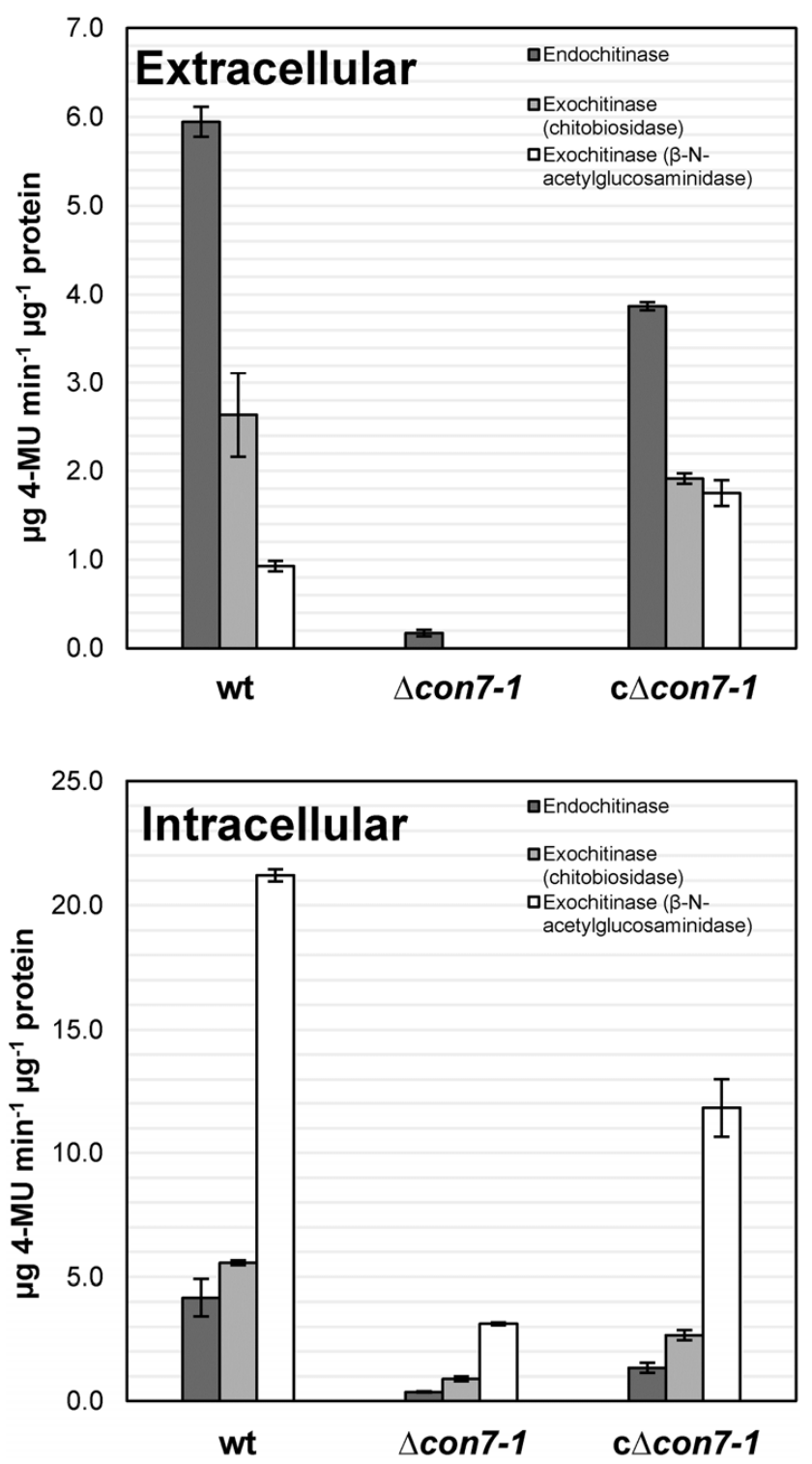

Fig. 6. Chitinase activity is drastically reduced in $\Delta c o n 7-1$. Intra- and extracellular protein extracts were obtained from germlings of the wild-type strain (wt), $\Delta$ con 7-1 mutant, and c $\Delta$ con $7-1$ complemented strains after 24 $\mathrm{h}$ growth in synthetic medium supplemented with $0.5 \%$ chitin. Endo- and exochitinase (chitobiosidase and $\beta-\mathrm{N}$-acetylglucosaminidase) activities were measured using the Chitinase Assay Kit Fluorimetric (Sigma). Specific chitinase activity is expressed as micrograms of 4-methylumbelliferone (4-MU) released from the appropriate substrate per microgram of protein. Bars represent standard errors calculated from two independent experiments with two replicates each. surface of the wild-type strain and $\mathrm{c} \Delta \operatorname{con} 7-1$ but had soaked into the surface of the mutant strain (Fig. 8), indicating that Con7-1 is required for maintaining full hydrophobicity of aerial hyphae.

Because glycolysis provides metabolites for energy production via oxidative phosphorylation, to verify the role of Con7 in the regulation of glycolysis or gluconeogenesis pathways, the intracellular ATP levels in $\Delta$ con 7 compared with the wildtype strain were quantified. A significant 2.4-fold increase of ATP in $\Delta \operatorname{con} 7$ (Fig. 9A) was observed, indicative of defects in carbon metabolism. Additionally, $\Delta$ con 7 showed a dramatic growth reduction in the presence of different glucose concentrations (Fig. 9B), supporting the fact of nutrient assimilation defects. To study whether this defect was due to alterations in the metabolism or in the transport of glucose, we determined intracellular glucose levels in the different strains as well as the amount of glucose remaining in the supernatants after growth in SM supplemented with either 0.05 or $2.5 \%$ glucose. Whereas no significant differences were detected in intracellular glucose accumulated by any strain (data not shown), the extracellular glucose remaining in the supernatants of $\Delta$ con $7-1$ after $24 \mathrm{~h}$ of growth in SM containing $2.5 \%$ glucose were significantly higher than in the wild-type strain (Fig. 9C), suggesting alterations in sugar transport in addition to carbon metabolism defects. Complementation of the $\Delta \operatorname{con} 7$ mutant with a wild-type copy of the gene restored all these phenotypes.

According to microarray results, $\Delta \operatorname{con} 7-1$ has altered expression of genes involved in metabolism of amino acids, carbohydrates, fatty acids, and lipids. To analyze the ability of the mutant to metabolize different carbon sources, microconidia of the different strains were inoculated on SM plates containing one of the following carbon sources: the monosaccharides arabinose or galactose; the disaccharides cellobiose, lactose, maltose, or saccharose; the complex sugar polygalacturonic acid; the sugar-derived alcohols mannitol or sorbitol; and the amino acids glycine, glutamic acid, or proline. After 7 days of growth, $\Delta$ con $7-1$ showed a significant reduction in colony diameter on most media assayed when compared with the wild

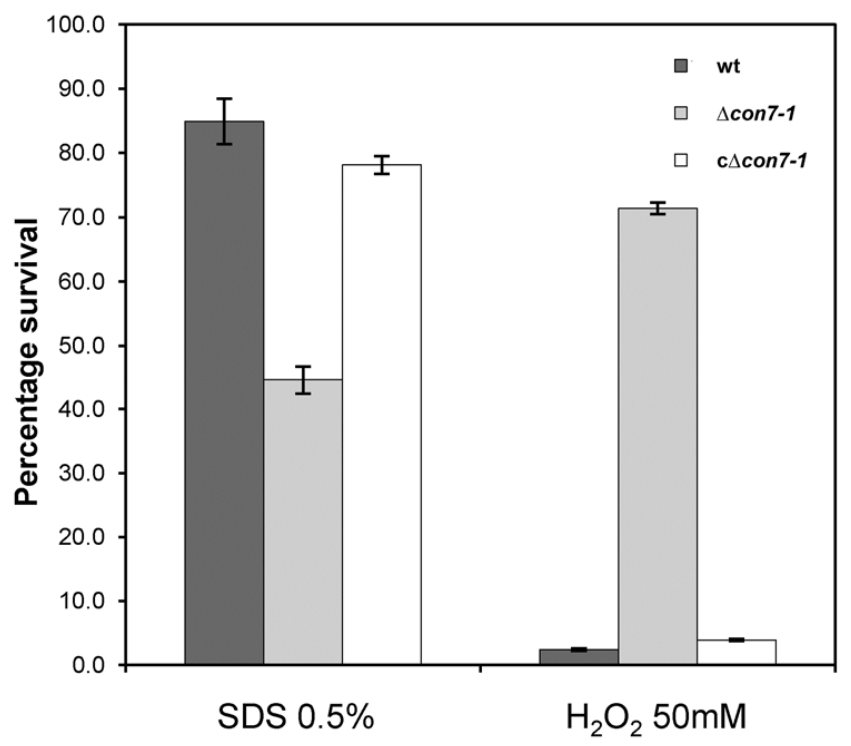

Fig. 7. Abiotic stress responses are altered in $\Delta$ con7-1. Microconidia of the wild-type strain (wt), $\Delta$ con $7-1$ mutant, and c $\Delta$ con $7-1$ complemented strain were treated with the indicated stressing compounds for $30 \mathrm{~min}$ at $28^{\circ} \mathrm{C}$ and $170 \mathrm{rpm}$, then inoculated on potato dextrose agar plates and grown for 2 days. Percent survival was calculated by comparison with the untreated controls for each strain. Bars represent standard errors calculated from three independent experiments with three replicates each. 
type or the $\mathrm{c} \Delta \operatorname{con} 7-1$ complemented strain, indicative of nutrient assimilation defects (Supplementary Fig. S8).

In order to determine the possible interaction of Con7-1 with more complex signaling cascades, we performed an in silico analysis of motifs present in promoters of Con7-1 positively regulated genes using the F-Match 1.0 software and the TRANSFAC database (Kel et al. 2006; Matys et al. 2006). An arbitrary sample set of 100 nonregulated genes was used as control. Transcription factor binding sites (TFBS) showing significant overrepresentation ratios $(>1.4)$ were found in most of the gene sets analyzed (Supplementary Table S4). These results suggest the existence of complex regulatory networks where Con7-1 might interact with different transcription regulators. The lack of functional Con7-1 would lead to pleiotropic effects as the altered phenotypes observed in the $\Delta \operatorname{con} 7-1$ deletion mutant.

\section{DISCUSSION}

The molecular bases for fungal morphogenetic development and pathogenicity are mostly unknown. In M. oryzae, the gene encoding TF Con7p has been previously shown to play an essential role in both processes (Odenbach et al. 2007; Shi and Leung 1995). Con7p orthologous sequences are present in the genome of all ascomycetes sequenced to date but they are absent in yeasts (Odenbach et al. 2007), suggesting that they may regulate essential functions common for filamentous fungi not existing in yeast. The $F$. oxysporum genome contains three genes coding for Con $7 \mathrm{p}$ orthologous proteins: con7-1 and two identical copies of con7-2 located on duplicated regions of LS chromosomes 3 and 6. F. oxysporum Con7 pro-
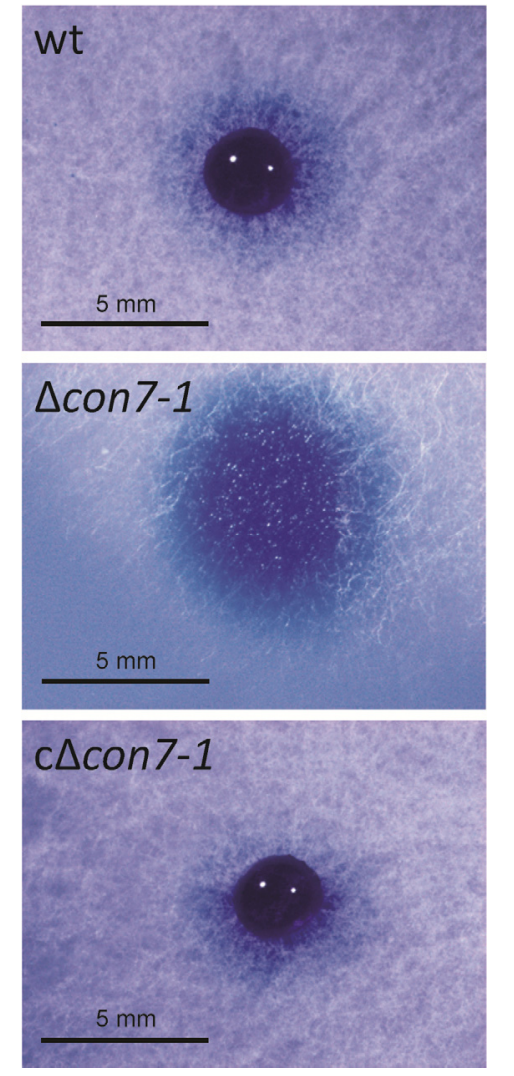

Fig. 8. Surface hydrophobicity is severely altered in $\Delta$ con7-1. Water droplets containing $0.12 \%$ bromophenol blue were spotted onto the surface of 4-day-old colonies from the indicated strains grown on minimal medium. Photographs were acquired after $1 \mathrm{~h}$ of incubation at room temperature. Bars $=5 \mathrm{~mm}$. teins contain conserved domains with significant identities to those of $M$. oryzae Con7p, including a nuclear localization signal, a $\mathrm{Cys}_{2} \mathrm{His}_{2}$ DNA binding domain, a coiled-coil region responsible for protein-protein interactions, and a proline/glutamine-rich C-terminal track that might form a transactivation domain. The conservation of these motifs in $F$. oxysporum Con7-1 supports its predicted regulatory function. In M. oryzae, two different con 7 transcripts were observed during different developmental stages (Odenbach et al. 2007). Similarly, the alternative splicing pattern affecting the $5^{\prime}$ end of $F$. oxysporum con7-1 pre-mRNA generated four different transcripts which could lead to four mature proteins containing specific phosphorylation sites. We speculate that, depending on their phosphory-

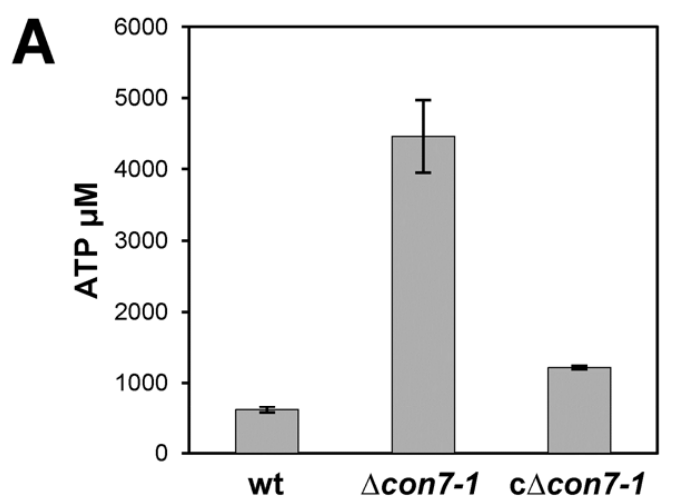

B
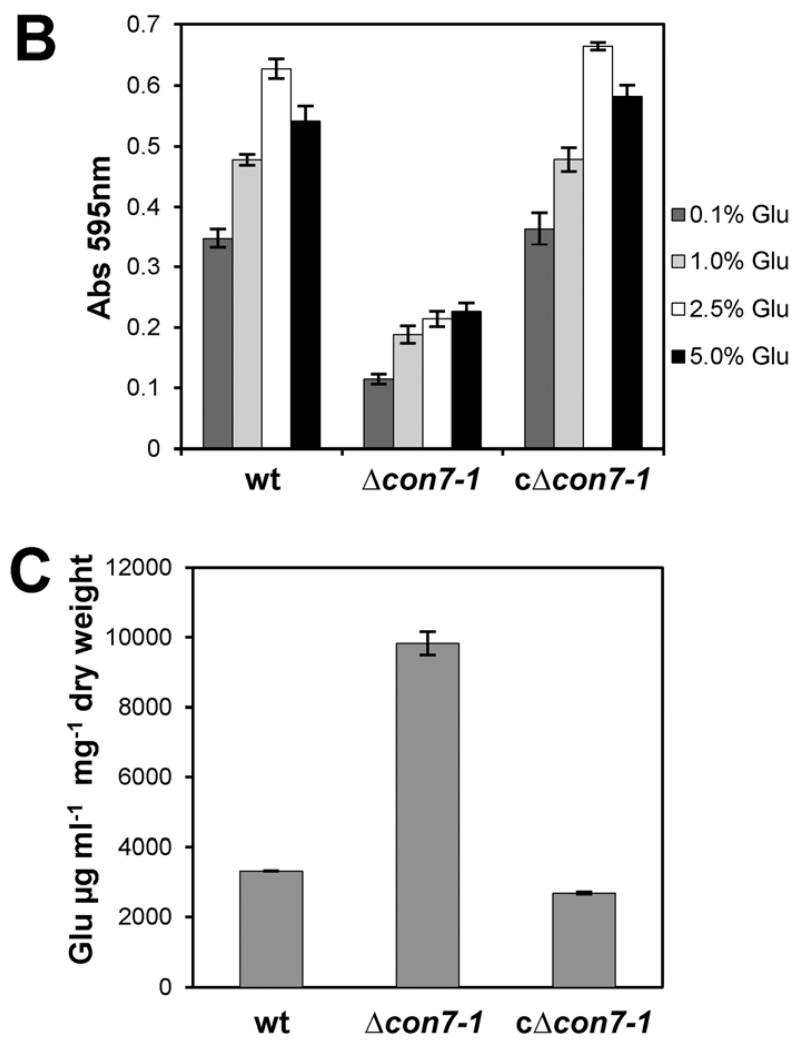

Fig. 9. Glucose metabolism is affected in $\Delta \operatorname{con} 7-1$. A, Intracellular ATP levels present in germlings of the indicated strains were quantified using the ATP determination kit (Invitrogen). B, Growth of the different strains was estimated by measuring the absorbance at $595 \mathrm{~nm}$. Microconidia were grown for $24 \mathrm{~h}$ in synthetic medium (SM) containing the indicated glucose concentrations. C, Extracellular glucose in culture supernatants after $24 \mathrm{~h}$ of growth in SM containing 2.5\% glucose calculated using the glucose determination kit GAGO (Sigma). Bars represent standard errors calculated from three independent experiments with three replicates each. 
lation stage, each protein version could function differentially, thus playing specific roles during fungal development. On the other hand, it cannot be excluded that the different versions of Con7-1 may interact for regulation of gene expression. Further studies would be necessary to understand the specific role of these protein versions during fungal growth and development as well as possible interactions with other proteins.

No detectable alterations were observed in morphology and virulence of $\Delta$ con 7-2 mutants, suggesting that this putative TF regulates dispensable functions in $F$. oxysporum biology. By contrast, deletion of con7-1 resulted in loss of ability to infect both tomato plants and $G$. mellonella larvae, supporting the idea that Con7-1 regulates common processes essential for pathogenicity in both infection models. Although the $\Delta$ con $7-1$ mutant was able to germinate and adhere to the root surface, it showed an easily wettable phenotype and did not colonize tomato stems, indicating impairment for penetration or colonization of plant tissues. In this sense, the $\Delta$ con $7-1$ mutant showed reduced expression of several genes encoding putative endopolygalacturanases and cellulases involved in degradation of plant cell walls (Di Pietro and Roncero 1998; Di Pietro et al. 2009; Garcia-Maceira et al. 2001), as well as genes responsible for SIX proteins essential for pathogenicity of $F$. oxysporum (Houterman et al. 2007, 2008, 2009; Lievens et al. 2009; Rep 2005; Rep et al. 2004; Takken and Rep 2010; Thatcher et al. 2012). Additionally, the $\Delta$ con $7-1$ mutant showed increased expression of a gene encoding a protein similar to O-acetyltransferase Cas1 shown to be essential for capsule structure and virulence in Cryptococcus neoformans (Janbon et al. 2001). In contrast to the wild-type strain, $C$. neoformans cas $1-\Delta$ disruption mutants contained a thinner capsule and were hypervirulent on mice. We hypothesize that the increased expression of the cas 1 ortholog in the $F$. oxysporum $\Delta$ con $7-1$ mutant could alter the cell wall structure, interfering with the course of infection, and therefore, would be also responsible for virulence modification as well as the different response of this mutant to perturbing agents such as hydrogen peroxide or SDS.

Morphogenetic development requires modification and plasticity of the fungal cell wall, which implies synthesis and remodeling of its components, including chitin and glucan. In contrast to $M$. oryzae Con7p, F. oxysporum Con7-1 was not found to regulate the expression of chitin synthases or chitinbinding proteins. Nonetheless, in our analyses, the $\Delta \operatorname{con} 7-1$ mutant showed significantly decreased expression of several genes encoding putative chitinases and glucanases, as well as a severe reduction in chitinase activity, suggesting that remodeling of the fungal cell wall would be seriously compromised, resulting in structural defects that might negatively influence growth and morphogenesis. In filamentous ascomycetes, chitinases are important during sporulation, spore germination, hyphal growth, and hyphal autolysis. In the yeast Saccharomyces cerevisiae, disruption of chitinase gene CTS 2 results in abnormal spore wall biosynthesis and failure to form mature asci (Giaever et al. 2002). Rhizopus oligosporus Chi3 chitinase has been postulated to function in loosening the cell wall at the hyphal tip, enabling turgor pressure to extend the hypha at the apex (Takaya et al. 1998a). Disruption of the gene encoding $A$. nidulans chitinase ChiA leads to decreased spore germination and lower hyphal growth rates (Takaya et al. 1998b).

The growth delay observed in the $\Delta$ con $7-1$ mutant, its preferential unipolar germination pattern, the generation of monosporic colonies with radial asymmetry, and the defects observed in branching and conidiation suggest that Con7-1 regulates morphogenesis and cell polarity, probably controlling the expression of Rho-type small monomeric GTPases either directly, in the case of Rho4, or indirectly, through the orthologs of yeast GTPase-activating proteins (GAPs) SAC7 and RAG6, that have been shown to activate $S$. cerevisiae RHO1 (Dunn and Shortle 1990; Schmidt et al. 2002) and Schizosaccharomyces pombe RHO2 and CDC42 (M. A. Villar-Tajadura, unpublished), respectively. In Neurospora crassa and A. nidulans, Rho4 plays a role in actin ring formation during hyphal septation (Rasmussen and Glass 2005; Si et al. 2010). In addition to its role during septum formation and sporulation, Rho4 ortholog RhoD is also necessary to ensure cell wall integrity in A. niger (Kwon et al. 2011). Although we detected no defect in septation in the $\Delta$ con $7-1$ mutant, it might be that $F$. oxysporum Rho4 plays a role in cell wall integrity through the regulation of lytic enzyme secretion, such as glucanases and chitinases, resembling the function of its ortholog in $S$. pombe during cytokinesis (Santos et al. 2005). S. cerevisiae SAC7 controls the actin cytoskeleton as a RHO1 GAP that negatively regulates the MAPK cell integrity pathway (Dunn and Shortle 1990; Martin et al. 2000; Schmidt et al. 2002), while its ortholog in A. niger, RhoA, is crucial for polarity establishment and viability (Kwon et al. 2011). The $S$. pombe GAP RGA6 negatively regulates $\mathrm{RHO} 2$ activity during cell wall biosynthesis and plays a role in cell morphology through the control of CDC42 activation (M. A. Villar-Tajadura, unpublished), whose ortholog in A. niger, CtfA, has been described to control actin dynamics (Kwon et al. 2011). On the other hand, F. oxysporum Con7-1 could exert development control regulating genes involved in the cytoskeleton, such as a putative calpain cysteine protease similar to $S$. cerevisiae CPL1 that is required for sporulation (Futai et al. 1999) or a putative phosphatidylinositol phosphate kinase similar to $S$. cerevisiae STT4 that functions in the control of the actin cytoskeleton (Foti et al. 2001). Additionally, $F$. oxysporum Con7-1 seems to play a role in development and morphogenesis, through the regulation of several genes involved in cell-cycle control, such as the Cdk5 cyclin-dependent kinase essential for cell polarity and virulence in the phytopathogenic fungus Ustilago maydis (Castillo-Lluva et al. 2007), or the Cdc 25 mitotic phosphatase that is required for $\mathrm{G} 2$ escape as well as for resistance to cell wall stressors after activation of the cell wall integrity pathway in $U$. maydis (Carbo and Perez-Martin 2010).

The reduction in branching observed in the $\Delta \operatorname{con} 7-1$ mutant could result in a lower number of conidiophores and, thus, a decreased number of conidia, which would lead to an inefficient colonization of host tissues. The $\Delta$ con7-1 mutant showed altered expression of several genes responsible for proteins previously shown to regulate conidiation, such as the A. nidulans cell wall protein PhiA (Melin et al. 2003) and the conidiation-specific protein Con-10 (Melin et al. 2003) or the $N$. crassa opsin Nop-1 (Bieszke et al. 2007). Interestingly, expression of these genes was enhanced in the $\Delta$ con $7-1$ mutant, suggesting a possible compensatory mechanism to maintain normal conidiation levels.

The defects in morphology and virulence detected in the $\Delta$ con $7-1$ mutant could be also influenced by failure in signal perception or transduction, as deduced from the number of genes encoding putative $G$ protein coupled receptors (GPCR), including the Pth11-like, GprC carbon sensor or the opsin receptors, as well as several serine-threonine protein kinases that were differentially represented in this strain, as previously reported in the $M$. oryzae con $7^{-}$mutant (Odenbach et al. 2007). Little information is available on the functions of fungal GPCR other than pheromone receptors, and their role in fungal pathogenicity is largely unknown (Li et al. 2007). The A. fumigatus $\mathrm{GprC}$ and $\mathrm{GprD}$ glucose receptors are essential regulators of colony growth, hyphal morphogenesis, and virulence (Gehrke et al. 2010). In the plant pathogen M. oryzae, the PTH11 GPCR is involved in appressorium formation and, thus, in pathogenicity, presumably through sensing surface hy- 
drophobicity and plant cutin monomers (DeZwaan et al. 1999). Further research on the characterization of these GPCR would help us to gain insight into the molecular mechanisms of signal perception in $F$. oxysporum.

An additional Con7-1-dependent group of genes comprise a number of predicted TF, suggesting that Con7-1 might indirectly control different cellular processes through the regulation of these intermediate regulators. According to our data, Con7-1 appears to regulate the general metabolism in $F$. oxysporum. It might be that, as a consequence of a failure in GPCR-mediated nutrient sensing, $\Delta$ con $7-1$ metabolism and, thus, growth is slowed down. Whether this is a direct consequence of con 7-1 deletion or a pleiotropic effect due to serious alterations in morphogenesis and development remains unknown. The in silico prediction of overrepresented TFBS in the promoters of Con7-1 positively regulated genes supports the hypothesis that Con7-1 interacts with complex regulatory networks, thus playing a key role in fungal development.

In summary, the results described in this study support the idea that Con7-1 plays a central role in the regulation of morphogenesis and virulence in $F$. oxysporum, probably through direct and indirect control of signal perception that triggers the activation of different pathways involved in both processes.

\section{MATERIALS AND METHODS}

\section{Fungal isolates and culture conditions.}

F. oxysporum f. sp. lycopersici wild-type strain 4287 (race 2) was obtained from J. Tello, Universidad de Almeria, Spain, and stored at $-80^{\circ} \mathrm{C}$ with $30 \%$ glycerol as microconidial suspension. The pathotype of the isolates was periodically confirmed by plant infection assays. For extraction of DNA and microconidia production, cultures were grown in PDB (Difco, Detroit) at $28^{\circ} \mathrm{C}$, as described previously (Di Pietro and Roncero 1998).

For phenotypic analysis of colony growth, water droplets containing $10^{3}$ freshly obtained microconidia were spread onto PDA plates and incubated at $28^{\circ} \mathrm{C}$ for several days, before being photographed. For analysis of germination and conidiation, $1.25 \times 10^{7}$ microconidia were inoculated into $25 \mathrm{ml}$ of $\mathrm{PDB}$ or $\mathrm{SM}\left(\mathrm{MgSO}_{4} \cdot 7 \mathrm{H}_{2} \mathrm{O}\right.$ at $0.2 \mathrm{~g} /$ liter, $\mathrm{KH}_{2} \mathrm{PO}_{4}$ at 0.2 $\mathrm{g} / \mathrm{liter}, \mathrm{KCl}$ at $0.2 \mathrm{~g} / \mathrm{liter}, \mathrm{NH}_{4} \mathrm{NO}_{2}$ at $1 \mathrm{~g} / \mathrm{liter}, \mathrm{FeSO}_{4}$ at 0.01 $\mathrm{g} / \mathrm{liter}, \mathrm{ZnSO}_{4}$ at $0.01 \mathrm{~g} / \mathrm{liter}, \mathrm{MnSO}_{4}$ at $0.01 \mathrm{~g} / \mathrm{liter}$, and glucose at $10 \mathrm{~g} /$ liter) and incubated at $28^{\circ} \mathrm{C}$ for several days with shaking at $170 \mathrm{rpm}$. The percentage of germination was determined by microscopic observations. Conidia were harvested and counted at the desired time points, as described previously (Di Pietro and Roncero 1998). To measure growth rates, $10^{6}$ microconidia of the different strains were inoculated into 96well plates containing $200 \mu \mathrm{l}$ of PDB or SM and incubated at $28^{\circ} \mathrm{C}$ for several days with shaking at $170 \mathrm{rpm}$. The absorbance at $595 \mathrm{~nm}$ of the cultures was measured periodically. To test sensitivity to abiotic stresses, freshly obtained microconidia were incubated for $30 \mathrm{~min}$ at $28^{\circ} \mathrm{C}$ with shaking in the presence of the corresponding stressing compound, then spread onto PDA plates and incubated for 2 to 3 days at $28^{\circ} \mathrm{C}$. Percent survival was recorded for each strain relative to the untreated controls. To determine surface hydrophobicity, 20- $\mu 1$ drops of water containing $0.12 \%$ bromophenol blue were placed on the surface of fungal colonies grown for 5 days on $\mathrm{MM}$ $\left(\mathrm{MgSO}_{4} \cdot 7 \mathrm{H}_{2} \mathrm{O}\right.$ at $0.5 \mathrm{~g} / \mathrm{liter}, \mathrm{KH}_{2} \mathrm{PO}_{4}$ at $1 \mathrm{~g} / \mathrm{liter}, \mathrm{KCl}$ at 0.5 g/liter, $\mathrm{NaNO}_{3}$ at $2 \mathrm{~g} /$ liter, sucrose at $30 \mathrm{~g} / \mathrm{liter}$, and agar at 15 $\mathrm{g} /$ liter) and allowed to stand for $1 \mathrm{~h}$, before being photographed.

For Calcofluor white $(\mathrm{CFW})$ staining, $5 \times 10^{7}$ freshly obtained microconidia were grown at $28^{\circ} \mathrm{C}$ for different time periods in $5 \mathrm{ml}$ of PDB with shaking at $170 \mathrm{rpm}$, then transferred to a solution containing $3.7 \%$ formaldehyde, $50 \mathrm{mM}$ phos- phate buffer ( $\mathrm{pH} 7.0$ ), and $0.2 \%$ Triton $\mathrm{X}-100$ for fixation and incubated at room temperature for $5 \mathrm{~min}$. Staining was achieved by incubating for $5 \mathrm{~min}$ at room temperature with $\mathrm{CFW}$ (Sigma) at $10 \mu \mathrm{g} \mathrm{ml}^{-1}$. Samples were then mounted in $10 \%$ phosphate buffer $(\mathrm{pH} 7.0)$ and $50 \%$ glycerol and screened by epifluorescence microscopy.

For analysis of gene expression, freshly obtained microconidia were incubated in PDB for $14 \mathrm{~h}$ (wild-type and c $\Delta$ con $7-1$ strains $)$ or $24 \mathrm{~h}$ ( $\Delta$ con $7-1$ mutant) and mycelia were harvested by filtration, washed three times in sterile doubledistilled water, frozen in liquid nitrogen, and stored at $-80^{\circ} \mathrm{C}$.

For microarray analysis, freshly obtained microconidia were germinated in PDB (pH 7.0) for $14 \mathrm{~h}$ (wild type) or $24 \mathrm{~h}$ ( $\Delta$ con7-1 mutant), transferred for $30 \mathrm{~min}$ to PDB $\mathrm{pH} 5.0$, and then transferred to PDB pH 7.0 for $30 \mathrm{~min}$. Finally, mycelia were harvested and stored as described above until use.

\section{Nucleic acid manipulations and sequence analysis.}

Total RNA and genomic DNA (gDNA) were extracted from F. oxysporum mycelia according to previously reported protocols (Aljanabi and Martinez 1997; Raeder and Broda 1985). The quality and quantity of extracted nucleic acids were determined by running aliquots in ethidium bromide-stained agarose gels and by spectrophotometric analysis in a NanoDrop ND1000 spectrophotometer (NanoDrop Technologies, Wilmington, DE, U.S.A.), respectively. Southern analyses and probe labeling were carried out as described previously (Di Pietro and Roncero 1998) using the nonisotopic digoxigenin-labeling kit (Roche Applied Science, Indianapolis, IN, U.S.A.). Sequencing of both DNA strands of the obtained clones was performed at STAB VIDA (Setubal, Portugal) using the Dyedeoxy Terminator Cycle Sequencing Kit (Applied Biosystems, Foster City, CA, U.S.A.). DNA and protein sequence databases were searched using the BLASTP algorithm (Altschul et al. 1990) at the National Centre for Biotechnology Information (Bethesda, MD, U.S.A.). Amino acid sequences were aligned using the CLUSTALW algorithm (Thompson et al. 1994) with the Bioedit 7.0.0 program.

For prediction of overrepresented TFBS in the promoters of downregulated genes in the $\Delta \operatorname{con} 7-1$ mutant, we used the program F-Match 1.0 software (Kel et al. 2006) and the TRANSFAC database (Matys et al. 2006) The analyses were set with default parameters (profile used: fungi; threshold $P$ value: 0.001; minimal site frequency: 0.1 ; maximal site frequency: 5.0). Genes were grouped into functional categories and their promoters were compared with an arbitrary sample set of 100 nonregulated genes used as control. Promoter sequences comprising $1.0-\mathrm{kb}$ regions upstream of the start codon of the selected genes were obtained from the $F$. oxysporum genome database.

\section{Targeted disruption and complementation.}

Targeted gene replacement of con $7-1$ was performed using the split marker technique (Catlett et al. 2003). Two overlapping gene deletion constructs were generated. One contained the promoter sequence of the con $7-1$ gene, obtained by amplification with the specific primer pair con7.1-25 and con7.1-31, fused to the $3^{\prime}$ end (approximately 75\%) of the Hyg resistance cassette (Carroll et al. 1994), amplified using primer pair trpC$8 \mathrm{~B}$ and hyg-G. The second fragment contained the terminator region of the target gene, obtained by amplification with the specific primer pair con7.1-32 and con7.1-34, fused to the $5^{\prime}$ end (approximately 75\%) of the Hyg resistance cassette, amplified using primer pair gpdA-15B and hyg-Y. These two overlapping DNA fragments were used to transform protoplasts of the $F$. oxysporum $\mathrm{f}$. sp. lycopersici 4287 wild-type strain, as reported previously (Di Pietro and Roncero 1998). 
The resulting $\mathrm{Hyg}^{\mathrm{R}}$ transformants were initially identified by PCR, and the homologous recombination events were confirmed by Southern analysis of selected transformants.

For simultaneous targeted replacement of the duplicated FOXG_12510/FOXG_14029 alleles (con7-2), a gene replacement vector $\mathrm{p} \Delta \mathrm{con} 7-\overline{2}$ was constructed as follows. A BamHI site was introduced at position 592 of the con $7-2$ coding region, using the overlapping method (Ho et al. 1989), with the primer pairs con7.2-1 and con7.2-6B or con7.2-4 con7.2-5B, and the final product was cloned into pGEM-T. A 2.7-kb BamHI fragment containing the hygromycin $\mathrm{B}$ resistance gene under the control of the $A$. nidulans gpdA promoter and the $\operatorname{trp} C$ terminator (Punt and van den Hondel 1992) was introduced at the new BamHI site in the con 7-2 coding region. A linear fragment containing the interrupted con $7-2$ allele was amplified with primers con7.2-1 and con7.2-4 and used to transform protoplasts of $F$. oxysporum f. sp. lycopersici strain 4287, according to the protocol described previously (Di Pietro and Roncero 1998). The resulting $\mathrm{Hyg}^{\mathrm{R}}$ transformants were initially identified by PCR, and the homologous recombination events were confirmed by Southern analysis of selected transformants.

For complementation of the $\Delta$ con $7-1$ mutant, a 2,523-bp fragment containing the complete con7-1 gene (including promoter and terminator regions) was amplified from gDNA using primers con7.1-25 and con7.1-6 and $P f u$ DNA polymerase (Promega, Madison, WI, U.S.A.). A 2.5-kb fragment containing the $\mathrm{Phl}$ resistance cassette was amplified from plasmid pAN8.1 (Punt and van den Hondel 1992) using primers gpdA$15 \mathrm{~B}$ and trpter-8B. Both fragments were used in the proportion 1:1 to co-transform the protoplast of strain $\Delta$ con 7-1 to $\mathrm{Phl}$ resistance. The resulting $\mathrm{Phl}^{\mathrm{R}}$ transformants were initially identified by PCR, and the functionality of the integrated DNA fragment was confirmed by RT-PCR analysis of selected transformants using primers con7.1-16 and con7.1-28.

\section{Gene expression analysis.}

Total RNA was treated with DNase I (Fermentas) and reverse transcribed into first-strand cDNA with M-MLV reverse transcriptase (Invitrogen, Carlsbad, CA, U.S.A.) using an oligo-dT antisense primer, in the presence of ribonuclease inhibitor RNasin Plus RNase inhibitor (Promega). Gene-specific primers were designed to flank introns when possible. Quantitative RT-PCR products were obtained using iQ SYBR Green Supermix (Bio-Rad, Munich) and an iCycler iQ real-time PCR System (Bio-Rad). Transcript levels were calculated by comparative $\Delta$ cycle threshold (Livak and Schmittgen 2001; Pfaffl 2001) and normalized to the actin gene. Expression values are presented relative to the expression in the wild-type strain.

Analyses of alternative intron splicing in con 7-1 transcripts were performed by RT-PCR. cDNA obtained from total RNA extracted from 14-h-grown wild-type germlings was amplified for 30 cycles with gene-specific primers con7.1-15 and con7.1-16. The amplified products were cloned into pSpark vector (Canvax Biotech SL, Córdoba, Spain) and sequenced as described above.

\section{Quantification of fungal biomass during plant infection.}

In planta quantification of fungal biomass was performed as described (Pareja-Jaime et al. 2010), with minor modifications. Plant roots were maintained immersed in microconidial sus-

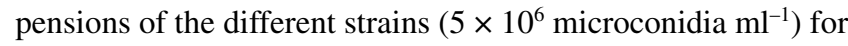
2 to 7 days. To avoid amplification of gDNA from external fungal mycelium that had not penetrated the roots, only the stems were collected for DNA analysis. Five plants were used per treatment. Quantitative PCR products were obtained using iQ SYBR Green Supermix (Bio-Rad), and relative amounts of fungal gDNA were calculated by comparative cycle threshold of the fungus-specific chs $V$ gene (Madrid et al. 2003) normalized to the tomato tomQB gene ( $\beta, 1-3$ glucanase). The experiment was repeated three times using independent infected tissues.

\section{Optical, fluorescence, transmission, and scanning electron microscopy.}

For optical and fluorescence microscopy analyses, cell aliquots were embedded on $1 \%$ agarose blocks and observed using the Nomarsky technique or the appropriate filter set, respectively, in a Zeiss Axio Imager M2 Dual Cam microscope (Carl Zeiss MicroImaging GmbH, Göttingen, Germany). Examination using epifluorescence was performed with UV light at 340 to $380 \mathrm{~nm}$ and the filter block (G 365, FT 395, LP 420). Images were captured with an Evolve Photometrics EM512 digital camera (Photometrics Technology, Tucson, AZ, U.S.A.) using the Axiovision 4.8 software and processed using Adobe Photoshop CS3 (Adobe Systems, Mountain View, CA, U.S.A.).

For video microscopy analysis, images were taken every 5 min using the microscope mentioned above and time-lapse picture series were converted to QuickTime movies.

For TEM, microconidia were initially fixed overnight at $4{ }^{\circ} \mathrm{C}$ in a mixture of $2.5 \%$ glutaraldehyde and $2 \%$ paraformaldehyde in $0.1 \mathrm{M}$ sodium cacodylate buffer, $\mathrm{pH} 7.0$, then washed in buffer and postfixed in $1 \%$ osmium tetroxide at $4^{\circ} \mathrm{C}$. After dehydration in an ethanol series, the samples were treated with propylene oxide and embedded in EMBed 812. After curing, the blocks were sectioned with a thickness of approximately $80 \mathrm{~nm}$ in an ultramicrotome and mounted on $\mathrm{Cu}$ grids. The samples were stained in $2 \%$ aqueous uranyl acetate for $2 \mathrm{~min}$ at $37^{\circ} \mathrm{C}$, then transferred to Reynolds lead citrate for $3 \mathrm{~min}$ at room temperature. Micrographs were obtained using a Philips CM 10 electron microscope.

For scanning electron microscopy, agar plugs containing 24h-grown germlings were fixed for $2 \mathrm{~h}$ in $2 \%$ glutaraldehyde at room temperature and dehydrated through a graded ethanol series (30 to $100 \%$ ) followed by $100 \%$ acetone for critical point drying. Samples were coated with a thin gold layer and observed with a JEOL 6300 scanning electron microscope.

\section{Plant and animal infection assays.}

Tomato root inoculation assays were performed as described (Di Pietro and Roncero 1998), using 2-week-old tomato seedlings ('Monika'; seed provided by Syngenta, Spain) and F. oxysporum strains; the roots were immersed in a suspension of $5 \times$ $10^{6}$ spores $\mathrm{ml}^{-1}$ for $30 \mathrm{~min}$, planted in vermiculite, and maintained in a growth chamber. Ten plants were used for each treatment. Severity of disease symptoms and plant survival were recorded daily for 30 days, as previously described (Lopez-Berges et al. 2012). Survival was estimated by the Kaplan-Meier method and compared among groups using the log-rank test. Data were analyzed with the software GraphPad Prism 4. Assays for invasive growth on tomato fruit ('Daniela') were carried out as described (Di Pietro et al. 2001). Virulence experiments were performed three times with similar results. For root adhesion experiments, plant roots were maintained immersed in microconidial suspensions of the different strains $\left(5 \times 10^{6}\right.$ microconidia $\left.\mathrm{ml}^{-1}\right)$ and incubated in a growth chamber at $28^{\circ} \mathrm{C}$ with shaking at $80 \mathrm{rpm}$ for several days, before being photographed.

G. mellonella larvae in the final larval stage were obtained from the company Animal Center S.C.P. (Valencia, Spain), and inoculated using a Burkard Auto Microapplicator $(0.1$ to $10 \mu \mathrm{l}$; Burkard Manufacturing Co. Limited, Hertfordshire, U.K.), as previously described (Navarro-Velasco et al. 2011). Fifteen larvae per treatment between 0.2 to $0.3 \mathrm{~g}$ in weight were inoc- 
ulated with a 1-ml syringe to inject $8 \mu \mathrm{l}$ of a microconidial suspension containing $1.5 \times 10^{5}$ spores. Larvae injected with PBS served as controls. Larvae were incubated in glass containers at $30^{\circ} \mathrm{C}$, and the number of dead larvae was scored daily. Larvae were considered dead when they displayed no movement in response to touch. The Mantel-Cox method was used to assess statistical significance of differences in survival among groups. Data were plotted using Graph Pad Prism software version 4 for Windows. Differences showing a $P$ value $<0.05$ were considered significant. Experiments were performed three times with similar results. Data presented are from one representative experiment.

\section{Transcriptional profiling.}

A custom-made $F$. oxysporum microarray chip in the 4-by44-K format (Agilent Technologies, Santa Clara, CA, U.S.A.) containing 45,220 distinct 60 -mer probes representing a total of 17,781 genes (GEO accession number GPL15804) was used in this study. Three different probes were used for genes larger than $885 \mathrm{bp}$ and two were used for those smaller than $885 \mathrm{bp}$. RNA was prepared from the wild-type or the $\Delta$ con7.1 strain grown as described above. In total, three arrays were analyzed per strain, each hybridized to an independent biological replicate. Microarray services were performed by the company Bioarray SL, an Agilent Certified Service Provider. Quality of RNA was analyzed using Nanodrop (Thermo Fisher Scientific) and Bioanalyzer 2100 (Agilent Technologies). RNA labeling with $\mathrm{Cy} 3$, array hybridization, and scanning were performed following Agilent's One-Color Microarray-Based Gene Expression Analysis protocol. Expression of a given gene was calculated based on the average processed data of the different probes corresponding to each gene. Data background subtraction was performed using the "normexp" method with an offset value of 10 . Interarray normalization was done using the "quantiles" method, which was implemented in R and included in the Bioconductor package (Workman et al. 2002). Statistical analysis was conducted using the Bioconductor packages Limma, Marray, affy, PCAmethods, and EMA. The unpaired $t$ test assuming equal variances was used for statistical comparison between the different data sets. A false discovery rate of 0.05 was considered significant.

\section{Determination of chitinase activity.}

Aliquots containing $4 \times 10^{8}$ microconidia were inoculated into $100 \mathrm{ml}$ of $\mathrm{PDB}$ and incubated at $28^{\circ} \mathrm{C}$ with shaking at 170

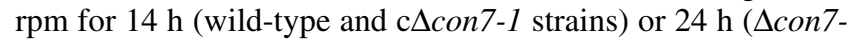
1 mutant). Germlings were harvested, washed twice with sterile double-distilled water, and transferred to $100 \mathrm{ml}$ of SM containing $0.5 \%$ chitin as sole carbon source. After $24 \mathrm{~h}$ of growth, culture supernatants were filtered to separate mycelia and spores, dialyzed against distilled water (dialysis membranes cut-off of $12 \mathrm{kDa}$ ), concentrated 100-fold using PEG 35,000, and stored at $-20^{\circ} \mathrm{C}$. Mycelia were washed, frozen at $-80^{\circ} \mathrm{C}$, and ground with a mortar and pestle under liquid nitrogen. Samples were homogenized in phosphate buffer $(0.05 \mathrm{M}, \mathrm{pH}$ 6.0 ) by vortexing, followed by $2 \mathrm{~min}$ of incubation at $4^{\circ} \mathrm{C}$. The homogenate was centrifuged $30 \mathrm{~min}$ at $10,000 \times g$ and $4^{\circ} \mathrm{C}$, and the supernatant was collected and stored at $-20^{\circ} \mathrm{C}$. The protein content of both culture supernatants and mycelia was quantified according to the method of Bradford using the BioRad protein assay, with bovine serum albumin as standard. Endo- and exochitinase activities were measured using the Fluorimetric Chitinase Assay Kit (Sigma) following the manufacturer's instructions. Chitinase activity was expressed as micrograms of 4-methylumbelliferone released from the substrate per micrograms of protein. Assays were performed in two independent experiments, each including two replicates.

\section{Determination of intracellular ATP levels.}

Aliquots containing $2.5 \times 10^{8}$ microconidia were grown in PDB for $24 \mathrm{~h}$ (wild-type and c $\Delta$ con $7-1$ strains) or $24 \mathrm{~h}$ ( $\Delta$ con 7-1 mutant). Mycelia were harvested, washed, and resuspended into $1 \mathrm{ml}$ of extraction buffer $(380 \mathrm{mM}$ trichloroacetic acid and $12.7 \mathrm{mM}$ EDTA). Cells were disrupted using a MiniBeadBeater homogenizer, followed by incubation at room temperature with shaking at $250 \mathrm{rpm}$ for $15 \mathrm{~min}$. The supernatant was harvested by centrifugation at $11,336 \times g$ for $15 \mathrm{~min}$ at $4{ }^{\circ} \mathrm{C}$. Aliquots $(10 \mu \mathrm{l}$ each) were used for quantification of ATP levels using the ATP determination kit (Invitrogen) following the instructions of the manufacturer. The amount of ATP in the samples was calculated from ATP standard curves. The assay was repeated three times with independent biological samples.

\section{Determination of intra- and extracellular glucose levels.}

Aliquots containing $4 \times 10^{8}$ microconidia were inoculated into $100 \mathrm{ml}$ of SM containing either 0.05 or $2.5 \%$ glucose and grown for $24 \mathrm{~h}$. Mycelia were harvested by filtration, washed, and lyophilized. After dry-weight determination, samples were resuspended into $250 \mu \mathrm{l}$ of $0.25 \mathrm{M} \mathrm{Na}_{2} \mathrm{CO}_{3}$ and disrupted using a Mini-BeadBeater homogenizer, followed by incubation at $95^{\circ} \mathrm{C}$ for $4 \mathrm{~h}$. The supernatant was harvested by centrifugation at $5,000 \times g$ for $3 \mathrm{~min}$. Aliquots $(14 \mu \mathrm{l} \mathrm{each})$ were used for quantification of intracellular glucose levels using the glucose determination kit GAGO (Sigma) following the instructions of the manufacturer. The amount of glucose remaining in culture supernatants from the different strains was also determined. Glucose levels were calculated from glucose standard curves and referred to mycelium dry-weight in each strain. The assay was repeated three times with independent biological samples.

\section{Accession numbers.}

Microarray data are deposited in the Gene Expression Omnibus database (approved GEO Series GSE59311) and can be accessed online.

\section{ACKNOWLEDGMENTS}

We thank E. M. Aguilera and I. Caballero for technical assistance. This research was supported by Junta de Andalucia (Proyecto de Excelencia CVI-7319) and the Spanish Ministerio de Economia y Competitividad (grant BIO2010-015505 and the Ramon y Cajal Program).

\section{LITERATURE CITED}

Aljanabi, S. M., and Martinez, I. 1997. Universal and rapid salt-extraction of high quality genomic DNA for PCR-based techniques. Nucleic Acids Res. 25:4692-4693.

Altschul, S. F., Gish, W., Miller, W., Myers, E. W., and Lipman, D. J. 1990. Basic local alignment search tool. J. Mol. Biol. 215:403-410.

Bieszke, J. A., Li, L., and Borkovich, K. A. 2007. The fungal opsin gene nop-1 is negatively-regulated by a component of the blue light sensing pathway and influences conidiation-specific gene expression in Neurospora crassa. Curr. Genet. 52:149-157.

Bluhm, B. H., Kim, H., Butchko, R. A., and Woloshuk, C. P. 2008. Involvement of ZFR1 of Fusarium verticillioides in kernel colonization and the regulation of FST1, a putative sugar transporter gene required for fumonisin biosynthesis on maize kernels. Mol. Plant Pathol. 9:203211.

Bravo-Ruiz, G., Ruiz-Roldán, C., and Roncero, M. I. 2013. Lipolytic system of the tomato pathogen Fusarium oxysporum f. sp. lycopersici Mol. Plant-Microbe Interact. 26:1054-1067.

Butchko, R. A., Brown, D. W., Busman, M., Tudzynski, B., and Wiemann, P. 2012. Lae1 regulates expression of multiple secondary metabolite gene clusters in Fusarium verticillioides. Fungal Genet. Biol. 49:602-612.

Calero-Nieto, F., Di Pietro, A., Roncero, M. I., and Hera, C. 2007. Role of the transcriptional activator $x \ln R$ of Fusarium oxysporum in regulation of xylanase genes and virulence. Mol. Plant-Microbe Interact. 20:977985. 
Caracuel, Z., Roncero, M. I., Espeso, E. A., Gonzalez-Verdejo, C. I., GarciaMaceira, F. I., and Di Pietro, A. 2003. The pH signalling transcription factor PacC controls virulence in the plant pathogen Fusarium oxysporum. Mol. Microbiol. 48:765-779.

Carbo, N., and Perez-Martin, J. 2010. Activation of the cell wall integrity pathway promotes escape from $\mathrm{G} 2$ in the fungus Ustilago maydis. PLoS Genet. 6:e1001009.

Carroll, A. M., Sweigard, J. A., and Valent, B. 1994. Improved vectors for selecting resistance to hygromycin. Fungal Genet. Newsl. 41:22.

Castillo-Lluva, S., Alvarez-Tabares, I., Weber, I., Steinberg, G., and PerezMartin, J. 2007. Sustained cell polarity and virulence in the phytopathogenic fungus Ustilago maydis depends on an essential cyclin-dependent kinase from the Cdk5/Pho85 family. J. Cell Sci. 120:1584-1595.

Catlett, N. L., Lee, B. N., Poder, O. C., and Turgeon, G. 2003. SplitMarker recombination for efficient targeted deletion of fungal genes. Fungal Genet. Newsl. 50:9-11.

Denisov, Y., Freeman, S., and Yarden, O. 2011. Inactivation of Snt2, a BAH/PHD-containing transcription factor, impairs pathogenicity and increases autophagosome abundance in Fusarium oxysporum. Mol. Plant Pathol. 12:449-461.

DeZwaan, T. M., Carroll, A. M., Valent, B., and Sweigard, J. A. 1999. Magnaporthe grisea Pth $11 \mathrm{p}$ is a novel plasma membrane protein that mediates appressorium differentiation in response to inductive substrate cues. Plant Cell 11:2013-2030.

Di Pietro, A., and Roncero, M. I. G. 1998. Cloning, expression, and role in pathogenicity of pg1 encoding the major extracellular endopolygalacturonase of the vascular wilt pathogen Fusarium oxysporum. Mol. Plant-Microbe Interact. 11:91-98

Di Pietro, A., García-Maceira, F., Meglecz, E., and Roncero, M. I. G. 2001. A MAP kinase of the vascular wilt fungus Fusarium oxysporum is essential for root penetration and pathogenesis. Mol. Microbiol. 39:1140-1152.

Di Pietro, A., Roncero, M. I. G., and Ruiz-Roldán, M. C. 2009. From tools of survival to weapons of destruction: Role of cell wall-degrading enzymes in plant infection. Pages 181-200 in: The Mycota. Plant Relationships. H. Deising, ed. Springer Verlag, Berlin.

Divon, H. H., Ziv, C., Davydov, O., Yarden, O., and Fluhr, R. 2006. The global nitrogen regulator, FNR1, regulates fungal nutrition-genes and fitness during Fusarium oxysporum pathogenesis. Mol. Plant Pathol. 7:485-497.

Dufresne, M., van der Lee, T., Ben M'barek, S., Xu, X., Zhang, X., Liu, T., Waalwijk, C., Zhang, W., Kema, G. H., and Daboussi, M. J. 2008. Transposon-tagging identifies novel pathogenicity genes in Fusarium graminearum. Fungal Genet. Biol. 45:1552-1561.

Dunn, T. M., and Shortle, D. 1990. Null alleles of SAC7 suppress temperature-sensitive actin mutations in Saccharomyces cerevisiae. Mol. Cell Biol. 10:2308-2314.

Foti, M., Audhya, A., and Emr, S. D. 2001. Sac1 lipid phosphatase and Stt4 phosphatidylinositol 4-kinase regulate a pool of phosphatidylinositol 4-phosphate that functions in the control of the actin cytoskeleton and vacuole morphology. Mol. Biol. Cell 12:2396-2411.

Futai, E., Maeda, T., Sorimachi, H., Kitamoto, K., Ishiura, S., and Suzuki, K. 1999. The protease activity of a calpain-like cysteine protease in Saccharomyces cerevisiae is required for alkaline adaptation and sporulation. Mol. Gen. Genet. 260:559-568.

Garcia-Maceira, F. I., Di Pietro, A., Huertas-Gonzalez, M. D., RuizRoldán, M. C., and Roncero, M. I. 2001. Molecular characterization of an endopolygalacturonase from Fusarium oxysporum expressed during early stages of infection. Appl. Environ. Microbiol. 67:2191-2196.

Garcia-Sanchez, M. A., Martin-Rodrigues, N., Ramos, B., de Vega-Bartol, J. J., Perlin, M. H., and Diaz-Minguez, J. M. 2010. fost12, the Fusarium oxysporum homolog of the transcription factor Ste12, is upregulated during plant infection and required for virulence. Fungal Genet. Biol. 47:216-225

Gehrke, A., Heinekamp, T., Jacobsen, I. D., and Brakhage, A. A. 2010. Heptahelical receptors GprC and GprD of Aspergillus fumigatus are essential regulators of colony growth, hyphal morphogenesis, and virulence. Appl. Environ. Microbiol. 76:3989-3998.

Giaever, G., Chu, A. M., Ni, L., Connelly, C., Riles, L., Veronneau, S., Dow, S., Lucau-Danila, A., Anderson, K., Andre, B., Arkin, A. P., Astromoff, A., El-Bakkoury, M., Bangham, R., Benito, R., Brachat, S., Campanaro, S., Curtiss, M., Davis, K., Deutschbauer, A., Entian, K. D., Flaherty, P., Foury, F., Garfinkel, D. J., Gerstein, M., Gotte, D., Guldener, U., Hegemann, J. H., Hempel, S., Herman, Z., Jaramillo, D. F., Kelly, D. E., Kelly, S. L., Kotter, P., LaBonte, D., Lamb, D. C., Lan, N., Liang, H., Liao, H., Liu, L., Luo, C., Lussier, M., Mao, R., Menard, P., Ooi, S. L., Revuelta, J. L., Roberts, C. J., Rose, M., Ross-Macdonald, P., Scherens, B., Schimmack, G., Shafer, B., Shoemaker, D. D., SookhaiMahadeo, S., Storms, R. K., Strathern, J. N., Valle, G., Voet, M., Volckaert, G., Wang, C. Y., Ward, T. R., Wilhelmy, J., Winzeler, E. A.,
Yang, Y., Yen, G., Youngman, E., Yu, K., Bussey, H., Boeke, J. D., Snyder, M., Philippsen, P., Davis, R. W., and Johnston, M. 2002. Functional profiling of the Saccharomyces cerevisiae genome. Nature 418:387-391.

Gu, Q., Zhang, C., Liu, X., and Ma, Z. 2014. A transcription factor FgSte12 is required for pathogenicity in Fusarium graminearum. Mol Plant Pathol. doi:10.1111/mpp.12155

Ho, S. N., Hunt, H. D., Horton, R. M., Pullen, J. K., and Pease, L. R. 1989. Site-directed mutagenesis by overlap extension using the polymerase chain-reaction. Gene 77:51-59.

Houterman, P. M., Speijer, D., Dekker, H. L., De Koster, C. G., Cornelissen, B. J., and Rep, M. 2007. The mixed xylem sap proteome of Fusarium oxysporum-infected tomato plants. Mol. Plant Pathol. 8:215-221.

Houterman, P. M., Cornelissen, B. J., and Rep, M. 2008. Suppression of plant resistance gene-based immunity by a fungal effector. PLoS Pathog. 4:e1000061

Houterman, P. M., Ma, L., van Ooijen, G., de Vroomen, M. J., Cornelissen, B. J., Takken, F. L., and Rep, M. 2009. The effector protein Avr2 of the xylem-colonizing fungus Fusarium oxysporum activates the tomato resistance protein I-2 intracellularly. Plant J. 58:970-978.

Imazaki, I., Kurahashi, M., Iida, Y., and Tsuge, T. 2007. Fow2, a Zn(II)2 Cys6-type transcription regulator, controls plant infection of the vascular wilt fungus Fusarium oxysporum. Mol. Microbiol. 63:737-753.

Janbon, G., Himmelreich, U., Moyrand, F., Improvisi, L., and Dromer, F. 2001. Cas $1 \mathrm{p}$ is a membrane protein necessary for the $O$-acetylation of the Cryptococcus neoformans capsular polysaccharide. Mol. Microbiol. 42:453-467.

Kel, A., Voss, N., Jauregui, R., Kel-Margoulis, O., and Wingender, E. 2006. Beyond microarrays: Find key transcription factors controlling signal transduction pathways. BMC Bioinf. 7 (Suppl. 2):S13.

Kim, H., and Woloshuk, C. P. 2008. Role of AREA, a regulator of nitrogen metabolism, during colonization of maize kernels and fumonisin biosynthesis in Fusarium verticillioides. Fungal Genet. Biol. 45:947-953.

Kim, H. K., Lee, S., Jo, S. M., McCormick, S. P., Butchko, R. A., Proctor, R. H., and Yun, S. H. 2013. Functional roles of FgLaeA in controlling secondary metabolism, sexual development, and virulence in Fusarium graminearum. PLoS One 8:e68441.

Kwon, M. J., Arentshorst, M., Roos, E. D., van den Hondel, C. A., Meyer, V., and Ram, A. F. 2011. Functional characterization of Rho GTPases in Aspergillus niger uncovers conserved and diverged roles of Rho proteins within filamentous fungi. Mol. Microbiol. 79:1151-1167.

Li, L., Wright, S. J., Krystofova, S., Park, G., and Borkovich, K. A. 2007. Heterotrimeric $G$ protein signaling in filamentous fungi. Annu. Rev. Microbiol. 61:423-452.

Lievens, B., Houterman, P. M., and Rep, M. 2009. Effector gene screening allows unambiguous identification of Fusarium oxysporum f. sp. lycopersici races and discrimination from other formae speciales. FEMS (Fed. Eur. Microbiol. Soc.) Microbiol. Lett. 300:201-215.

Lints, R., Davis, M. A., and Hynes, M. J. 1995. The positively acting amdA gene of Aspergillus nidulans encodes a protein with two $\mathrm{C}_{2} \mathrm{H}_{2}$ zinc-finger motifs. Mol. Microbiol. 15:965-975.

Livak, K. J., and Schmittgen, T. D. 2001. Analysis of relative gene expression data using real-time quantitative PCR and the 2(-delta delta $\mathrm{C}(\mathrm{T})$ ) method. Methods 25:402-408.

Lopez-Berges, M. S., Di Pietro, A., Daboussi, M. J., Wahab, H. A., Vasnier, C., Roncero, M. I., Dufresne, M., and Hera, C. 2009. Identification of virulence genes in Fusarium oxysporum f. sp. lycopersici by large-scale transposon tagging. Mol. Plant Pathol. 10:95-107.

Lopez-Berges, M. S., Capilla, J., Turra, D., Schafferer, L., Matthijs, S., Jochl, C., Cornelis, P., Guarro, J., Haas, H., and Di Pietro, A. 2012. HapX-mediated iron homeostasis is essential for rhizosphere competence and virulence of the soilborne pathogen Fusarium oxysporum Plant Cell 24:3805-3822.

Lopez-Berges, M. S., Hera, C., Sulyok, M., Schafer, K., Capilla, J., Guarro, J., and Di Pietro, A. 2013. The velvet complex governs mycotoxin production and virulence of Fusarium oxysporum on plant and mammalian hosts. Mol. Microbiol. 87:49-65.

Lopez-Fernandez, L., Ruiz-Roldán, C., Pareja-Jaime, Y., Prieto, A., Khraiwesh, H., and Roncero, M. I. 2013. The Fusarium oxysporum gnt 2 , encoding a putative $\mathrm{N}$-acetylglucosamine transferase, is involved in cell wall architecture and virulence. PLoS One 8:e84690.

Lysoe, E., Pasquali, M., Breakspear, A., and Kistler, H. C. 2011. The transcription factor FgStuAp influences spore development, pathogenicity, and secondary metabolism in Fusarium graminearum. Mol. PlantMicrobe Interact. 24:54-67.

Madrid, M. P., Di Pietro, A., and Roncero, M. I. 2003. Class V chitin synthase determines pathogenesis in the vascular wilt fungus Fusarium oxysporum and mediates resistance to plant defence compounds. Mol. Microbiol. 47:257-266.

Martin, H., Rodriguez-Pachon, J. M., Ruiz, C., Nombela, C., and Molina, 
M. 2000. Regulatory mechanisms for modulation of signaling through the cell integrity S1t2-mediated pathway in Saccharomyces cerevisiae. J. Biol. Chem. 275:1511-1519.

Martin-Urdiroz, M., Roncero, M. I., Gonzalez-Reyes, J. A., and RuizRoldán, C. 2008. ChsVb, a class VII chitin synthase involved in septation, is critical for pathogenicity in Fusarium oxysporum. Eukaryot. Cell 7:112-121.

Matys, V., Kel-Margoulis, O. V., Fricke, E., Liebich, I., Land, S., BarreDirrie, A., Reuter, I., Chekmenev, D., Krull, M., Hornischer, K., Voss, N., Stegmaier, P., Lewicki-Potapov, B., Saxel, H., Kel, A. E., and Wingender, E. 2006. TRANSFAC and its module TRANSCompel: Transcriptional gene regulation in eukaryotes. Nucleic Acids Res. 34:D108-D110.

Melin, P., Schnurer, J., and Wagner, E. G. 2003. Characterization of phiA, a gene essential for phialide development in Aspergillus nidulans. Fungal Genet. Biol. 40:234-241.

Michielse, C. B., van Wijk, R., Reijnen, L., Cornelissen, B. J., and Rep, M. 2009a. Insight into the molecular requirements for pathogenicity of Fusarium oxysporum f. sp. lycopersici through large-scale insertional mutagenesis. Genome Biol. 10:R4.

Michielse, C. B., van Wijk, R., Reijnen, L., Manders, E. M. M., Boas, S., Olivain, C., Alabouvette, C., and Rep, M. 2009b. The nuclear protein Sge1 of Fusarium oxysporum is required for parasitic growth. PLoS Pathog. 5:e1000637.

Myung, K., Li, S., Butchko, R. A., Busman, M., Proctor, R. H., Abbas, H. K., and Calvo, A. M. 2009. FvVE1 regulates biosynthesis of the mycotoxins fumonisins and fusarins in Fusarium verticillioides. J. Agric. Food Chem. 57:5089-5094.

Myung, K., Zitomer, N. C., Duvall, M., Glenn, A. E., Riley, R. T., and Calvo, A. M. 2012. The conserved global regulator VeA is necessary for symptom production and mycotoxin synthesis in maize seedlings by Fusarium verticillioides. Plant Pathol. 61:152-160.

Navarro-Velasco, G. Y., Prados-Rosales, R. C., Ortíz-Urquiza, A., Quesada-Moraga, E., and Di Pietro, A. 2011. Galleria mellonella as model host for the trans-kingdom pathogen Fusarium oxysporum. Fungal Genet. Biol. 48:1124-1129.

Odenbach, D., Breth, B., Thines, E., Weber, R. W., Anke, H., and Foster, A. J. 2007. The transcription factor $\operatorname{Con} 7 p$ is a central regulator of infection-related morphogenesis in the rice blast fungus Magnaporthe grisea. Mol. Microbiol. 64:293-307.

Odenbach, D., Thines, E., Anke, H., and Foster, A. J. 2009. The Magnaporthe grisea class VII chitin synthase is required for normal appressorial development and function. Mol. Plant Pathol. 10:81-94.

Ok, S. H., Jeong, H. J., Bae, J. M., Shin, J. S., Luan, S., and Kim, K. N. 2005. Novel CIPK1-associated proteins in Arabidopsis contain an evolutionarily conserved $\mathrm{C}$-terminal region that mediates nuclear localization. Plant Physiol. 139:138-150.

Pareja-Jaime, Y., Martin-Urdiroz, M., Roncero, M.I., Gonzalez-Reyes, J.A., and Ruiz-Roldán, C. 2010. Chitin synthase-deficient mutant of Fusarium oxysporum elicits tomato plant defence response and protects against wild-type infection. Mol. Plant Pathol. 11:479-493.

Pfaffl, M.W. 2001. A new mathematical model for relative quantification in real-time RT-PCR. Nucleic Acids Res. 29:e45.

Pohlmann, J., and Fleig, U. 2010. Asp1, a conserved 1/3 inositol polyphosphate kinase, regulates the dimorphic switch in Schizosaccharomyces pombe. Mol. Cell Biol. 30:4535-4547.

Punt, P. J., and van den Hondel, C. A. 1992. Transformation of filamentous fungi based on hygromycin B and phleomycin resistance markers. Methods Enzymol. 216:447-457.

Raeder, U., and Broda, P. 1985. Rapid preparation of DNA from filamentous fungi. Lett. Appl. Microbiol. 1:17-20.

Ramos, B., Alves-Santos, F. M., Garcia-Sanchez, M. A., MartinRodrigues, N., Eslava, A. P., and Diaz-Minguez, J. M. 2007. The gene coding for a new transcription factor (ftf1) of Fusarium oxysporum is only expressed during infection of common bean. Fungal Genet. Biol. 44:864-876

Rasmussen, C. G., and Glass, N. L. 2005. A Rho-type GTPase, rho-4, is required for septation in Neurospora crassa. Eukaryot. Cell 4:19131925.

Rep, M. 2005. Small proteins of plant-pathogenic fungi secreted during host colonization. FEMS (Fed. Eur. Microbiol. Soc.) Microbiol. Lett. 253:19-27.

Rep, M., van der Does, H. C., Meijer, M., van Wijk, R., Houterman, P. M., Dekker, H. L., de Koster, C. G., and Cornelissen, B. J. 2004. A small, cysteine-rich protein secreted by Fusarium oxysporum during coloniza- tion of xylem vessels is required for I-3-mediated resistance in tomato. Mol. Microbiol. 53:1373-1383.

Rispail, N., and Di Pietro, A. 2009. Fusarium oxysporum Ste12 controls invasive growth and virulence downstream of the Fmk1 MAPK cascade. Mol. Plant-Microbe Interact. 22:830-839.

Ruiz-Roldan, M. C., Kohli, M., Roncero, M. I., Philippsen, P., Di Pietro, A., and Espeso, E. A. 2010. Nuclear dynamics during germination, conidiation, and hyphal fusion of Fusarium oxysporum. Eukaryot. Cell 9:1216-1224

Santos, B., Martin-Cuadrado, A. B., Vazquez de Aldana, C. R., del Rey, F., and Perez, P. 2005. Rho4 GTPase is involved in secretion of glucanases during fission yeast cytokinesis. Eukaryot. Cell 4:1639-1645.

Schmidt, A., Schmelzle, T., and Hall, M. N. 2002. The RHO1-GAPs SAC7, BEM2 and BAG7 control distinct RHO1 functions in Saccharomyces cerevisiae. Mol. Microbiol. 45:1433-1441.

Seong, K., Hou, Z., Tracy, M., Kistler, H. C., and Xu, J. R. 2005. Random insertional mutagenesis identifies genes associated with virulence in the wheat scab fungus Fusarium graminearum. Phytopathology 95:744750 .

Shi, Z., and Leung, H. 1995. Genetic analysis of sporulation in Magnaporthe grisea by chemical and insertional mutagenesis. Mol. PlantMicrobe Interact. 8:949-959.

Shi, Z., Christian, D., and Leung, H. 1998. Interactions between spore morphogenetic mutations affect cell types, sporulation, and pathogenesis in Magnaporthe grisea. Mol. Plant-Microbe Interact. 11:199-207.

Si, H., Justa-Schuch, D., Seiler, S., and Harris, S. D. 2010. Regulation of septum formation by the Bud3-Rho4 GTPase module in Aspergillus nidulans. Genetics 185:165-176.

Takaya, N., Yamazaki, D., Horiuchi, H., Ohta, A., and Takagi, M. 1998a. Intracellular chitinase gene from Rhizopus oligosporus: Molecular cloning and characterization. Microbiology 144:2647-2654.

Takaya, N., Yamazaki, D., Horiuchi, H., Ohta, A., and Takagi, M. 1998b. Cloning and characterization of a chitinase-encoding gene (chiA) from Aspergillus nidulans, disruption of which decreases germination frequency and hyphal growth. Biosci. Biotechnol. Biochem. 62:60-65.

Takken, F., and Rep, M. 2010. The arms race between tomato and Fusarium oxysporum. Mol. Plant Pathol. 11:309-314.

Thatcher, L. F., Gardiner, D. M., Kazan, K., and Manners, J. M. 2012. A highly conserved effector in Fusarium oxysporum is required for full virulence on Arabidopsis. Mol. Plant-Microbe Interact. 25:180-190.

Thompson, J. D., Higgins, D. G., and Gibson, T. J. 1994. Clustal W improving the sensitivity of progressive multiple sequence alignment through sequence weighting, position specific gap penalties and weight matrix choice. Nucleic Acids Res. 22:4673-4680.

Tudzynski, B., Homann, V., Feng, B., and Marzluf, G. A. 1999. Isolation, characterization and disruption of the areA nitrogen regulatory gene of Gibberella fujikuroi. Mol. Gen. Genet. 261:106-114.

Wang, Y., Liu, W., Hou, Z., Wang, C., Zhou, X., Jonkers, W., Ding, S. Kistler, H. C., and Xu, J. R. 2011. A novel transcriptional factor important for pathogenesis and ascosporogenesis in Fusarium graminearum. Mol. Plant-Microbe Interact. 24:118-128.

Wiemann, P., Brown, D. W., Kleigrewe, K., Bok, J. W., Keller, N. P. Humpf, H. U., and Tudzynski, B. 2010. FfVel1 and FfLae1, components of a velvet-like complex in Fusarium fujikuroi, affect differentiation, secondary metabolism and virulence. Mol. Microbiol. Published online.

Workman, C., Jensen, L. J., Jarmer, H., Berka, R., Gautier, L., Nielser, H. B., Saxild, H. H., Nielsen, C., Brunak, S., and Knudsen, S. 2002. A new non-linear normalization method for reducing variability in DNA microarray experiments. Genome Biol. 3:research0048.

\section{AUTHOR-RECOMMENDED INTERNET RESOURCES}

Bioconductor package: www.r-project.org

BioEdit program: www.mbio.ncsu.edu/bioedit/bioedit.html

CBS prediction tool: www.cbs.dtu.dk/services

F. oxysporum genome database:

www.broadinstitute.org/annotation/genome/fusarium_group

Gene Expression Omnibus database:

www.ncbi.nlm.nih.gov/geo/query/acc.cgi?acc=GSE59311

KEGG pathways: www.genome.jp/kegg/pathway.html

PROSITE tool: www.expasy.ch/prosite

TRANSFAC database: www.gene-regulation.com/pub/programs.html

UniProt-GO Annotation database: www.ebi.ac.uk/GOA 